\title{
An uncertainty-focused database approach to extract spatiotemporal trends from qualitative and
}

discontinuous lake-status histories

\section{De Cort, Gijs}

Limnology Unit, Department of Biology, Ghent University, Belgium

Division of Ocean and Climate Physics, Lamont-Doherty Earth Observatory, Columbia University, USA

Department of Earth Sciences, Royal Museum for Central Africa, Belgium

E-mail: gijs.decort@ugent.be

\section{Chevalier, Manuel}

Institute of Earth Surface Dynamics, University of Lausanne, Switzerland

Institute of Geosciences, Sect. Meteorology, Rheinische Friedrich-Wilhelms-Universität Bonn, Germany

E-mail: manuel.chevalier@unil.ch

Twitter: @ChevalierManu

\section{Burrough, Sallie L.}

School of Geography and the Environment, University of Oxford, UK

E-mail: sallie.burrough@ouce.ox.ac.uk

Twitter: @SLBurrough

\section{Chen, Christine Y.}

Massachusetts Institute of Technology-Woods Hole Oceanographic Institution Joint Program in Oceanography, USA

Department of Earth, Atmospheric and Planetary Sciences, Massachusetts Institute of Technology, USA

Division of Geological and Planetary Sciences, California Institute of Technology, USA

Now at Division of Nuclear and Chemical Sciences, Lawrence Livermore National Laboratory, USA

E-mail: chen127@1lnl.gov

Twitter: @earth2christine

\section{Harrison, Sandy P.}

School of Archaeology, Geography and Environmental Science, University of Reading, UK

E-mail: s.p.harrison@ reading.ac.uk

The contents of this manuscript were submitted to Quaternary Science Reviews as an original research article on September 3, 2020 and accepted for publication on February 23, 2021. The version stored here on EarthArXiv represents a revised version of the originally submitted manuscript after peer review. Subsequent versions of this manuscript, as well as the final version published in Quaternary Science Reviews, may contain slightly altered content. Data and documentation related to this manuscript will be freely available on the open data repository Zenodo (https://doi.org/10.5281/zenodo.4494804) upon publication of the final version.

Where appropriate, please refer to the final version of this work:

De Cort, G., Chevalier, M., Burrough, S.L., Chen, C.Y., Harrison, S.P. An uncertainty-focused database approach to extract spatiotemporal trends from qualitative and discontinuous lake-status histories. Quaternary Science Reviews. In press, doi to be assigned.

We welcome comments on this manuscript. Please address these to Gijs De Cort (gijs.decort@ugent.be) or Manuel Chevalier (manuel.chevalier@unil.ch). 


\section{An uncertainty-focused database approach to extract spatiotemporal trends from qualitative and discontinuous lake-status histories}

1,2,3,* De Cort, Gijs; ${ }^{4,5}$ Chevalier, Manuel; ${ }^{6}$ Burrough, Sallie L.; ${ }^{78,9,+}$ Chen, Christine Y.; ${ }^{10}$ Harrison, Sandy P.

${ }^{1}$ Limnology Unit, Department of Biology, Ghent University, Belgium

${ }^{2}$ Division of Ocean and Climate Physics, Lamont-Doherty Earth Observatory, Columbia University, USA

${ }^{3}$ Department of Earth Sciences, Royal Museum for Central Africa, Belgium

${ }^{4}$ Institute of Earth Surface Dynamics, University of Lausanne, Switzerland

${ }^{5}$ Institute of Geosciences, Sect. Meteorology, Rheinische Friedrich-Wilhelms-Universität Bonn, Germany

${ }^{6}$ School of Geography and the Environment, University of Oxford, UK

${ }^{7}$ Massachusetts Institute of Technology-Woods Hole Oceanographic Institution Joint Program in Oceanography, USA

${ }^{8}$ Department of Earth, Atmospheric and Planetary Sciences, Massachusetts Institute of Technology, USA

${ }^{9}$ Division of Geological and Planetary Sciences, California Institute of Technology, USA

${ }^{10}$ School of Archaeology, Geography and Environmental Science, University of Reading, UK

+Now at Division of Nuclear and Chemical Sciences, Lawrence Livermore National Laboratory, USA

*Corresponding author:

E-mail: gijs.decort@ugent.be

Current address: Limnology Unit, Department of Biology, Ghent University, K.L. Ledeganckstraat 35, 9000 Ghent, Belgium 


\begin{abstract}
Changes in lake status are often interpreted as palaeoclimate indicators due to their dependence on precipitation and evaporation. The Global Lake Status Database (GLSDB) has since long provided a standardised synopsis of qualitative lake status over the last $30,000{ }^{14} \mathrm{C}$ years. Potential sources of uncertainty however are not recorded in the GLSDB. Here we present an updated and improved relational-database framework that incorporates uncertainty in both chronology and the interpretation of palaeoenvironmental data. The database uses peerreviewed palaeolimnological studies to produce a consensus on qualitative lake-status histories, whose chronologies are revised and standardized through the recalibration of radiocarbon dates and the application of Bayesian age-depth modelling for stratigraphic archives. Quantitative information on absolute water-level elevation is preserved if available from geomorphological sources. We also propose a new probabilistic analytical framework that accounts for these uncertainties to reconstruct synoptic, integrated environmental signals. The process is based on a Monte Carlo algorithm that iteratively samples individual lake-status histories within the limits of their uncertainties to produce many possible scenarios. We then use Recursively-Subtracted Empirical Orthogonal Function analysis to extract dominant patterns of lake-status variability from these scenarios.
\end{abstract}

As a proof of concept, we apply this framework to 67 sites in eastern and southern Africa whose lake-status histories cover part of the late Pleistocene and/or Holocene. We show that, despite the sometimes large temporal and interpretation uncertainties, and the inclusion of highly discontinuous lake-status time series, identifying the major known millennial-scale climatic phases during the last 20,000 years is possible. Our framework was also able to identify an antiphased response between the lake basins in eastern and interior southern Africa to these changes. We propose that our new database and methodology framework serves as a template for efficient lakestatus data synthesis, encourages the incorporation of lake-status data in more palaeoclimate syntheses, and expands the possibilities for the use of such data in the evaluation of climate models.

\title{
Keywords
}

Lake status; lake level; palaeolimnology; palaeoclimatology; relational database; data uncertainty; Monte Carlo algorithm; Recursively-Subtracted Empirical Orthogonal Function; Africa; Quaternary

\section{Highlights}

- We present a new database format to synthesize lake-status histories, conserving data uncertainty in both chronology and lake status.

- A combination of Monte Carlo iterative sampling and recursively-subtracted empirical orthogonal function analysis is employed to extract dominant patterns from uncertain lake-status histories.

- A proof-of-concept study highlights the dominant millennial-scale palaeoclimatic trends of eastern and southern Africa of the last 20,000 years. 


\section{Introduction}

Understanding hydroclimate dynamics on timescales longer than a few decades depends largely on natural environmental archives that have recorded past climate changes. Changes in lake volume and/or area provide important information about past hydroclimates because they reflect changes in the balance of precipitation and evaporation over the lake and its catchment (Cheddadi et al., 1997; Harrison et al., 2002). The first efforts to reconstruct late-Quaternary palaeo-hydroclimate dynamics from lake data started in the late 1970's (Street and Grove, 1979) and led to the creation of several regional compilations (e.g., Harrison, 1989; Fang, 1991; Harrison, 1993; Harrison et al., 1993; Tarasov et al., 1994; Yu and Harrison, 1996; Harrison et al., 1996; Jolly et al., 1998). These regional databases were subsequently homogenised and integrated into the first Global Lake Status Database (GLSDB; Qin et al., 1998) that contained histories of 'lake status' (a term that covers all parameters of lake size, i.e. depth, level, area and volume) across the world spanning some or all of the last 30,000 radiocarbon years ( 34,000 cal yr BP). Initially, the GLSDB records were categorised into three qualitative lake-status classes - 'low', 'intermediate' and 'high' - at 1000 radiocarbon-year intervals. Later, this structure was adapted to provide continuous records and allow an assessment of dating quality and flexible definitions of status class. The GLSDB has been used to assess palaeoenvironmental changes since the Last Glacial Maximum (LGM) and to evaluate climate-model hindcasting performance for key time windows in the past (e.g., Qin et al., 1998; Kohfeld and Harrison, 2000; Coe and Harrison, 2002; Tierney et al., 2011; Bartlein et al., 2017).

Unfortunately, the GLSDB was last updated in the late 1990s and does not include the many new palaeolimnological studies published since then. An update of the chronologies of the records stored in the database is also necessary because all the chronologies were reported as uncalibrated radiocarbon dates, and because many other geochronological methods have since been applied to palaeolimnological archives (e.g., Kutterolf et al., 2016; Roberts et al., 2018; Chen et al., 2020; Hatfield et al., 2020). In parallel, awareness has grown regarding the necessity to account for uncertainties when interpreting paleoenvironmental records and their age models (e.g., Telford et al., 2004; Heegaard et al., 2005; Blaauw, 2010; Blaauw and Christen, 2011; Parnell et al., 2011; Breitenbach 2012). In its original form, the GLSDB cannot account for such uncertainties. One particular consequence of such limited consideration of uncertainties is that all the records are treated as equivalent. Such an assumption is obviously problematic as some records are more informative than others, due to better dating and/or more straightforward interpretations.

This paper presents a new relational database structure that efficiently stores lake-status histories, including both chronological and status uncertainties, and demonstrates how such an uncertainty-focused database can enable more complex reconstructions of past environmental change. As a proof-of-concept, we present a new compilation of 67 late-Quaternary lake-status histories from eastern and southern Africa (ESA), many of which are discrete and discontinuous. We employ a new probabilistic approach based on a Monte Carlo (MC) algorithm and empirical orthogonal functions (EOFs) to identify the dominant hydroclimate features across ESA during the last 20,000 years. Finally, based on the results of this concept study, we explore and discuss the relative strengths and weaknesses of our framework. 


\section{Lake status as an indicator of past climate}

The balance between precipitation and evaporation (P-E) exerts a universal control on lacustrine systems by regulating lake volume, which itself depends on lake depth and surface area (Mason et al., 1994; Cheddadi et al., 1996; Harrison et al., 2002). Responses of lake volume to climatic change are most striking in endorheic, or 'closed' lakes, i.e. lakes without an (above-ground) outflow where most or all water leaving the lake is lost through evaporation. Closed lakes are found most often in semi-arid environments, where catchment evapotranspiration exceeds water input, thus constraining lake-level equilibria below overflow level (Meybeck, 1995). While the response of exorheic, or 'open' lakes, to climatic change is often less dramatic, these also undergo lake-level changes if changes in the hydrologic budget are not compensated by inflow/outflow adjustments (Cheddadi et al., 1996). On longer time scales, many lakes can be classified as transitional, shifting between open and closed states as changing climate controls their water balance (Kalff, 2001).

Past lake status is derived from two main lines of evidence. The first source is geomorphic features formed by marginal processes that reflect displacements of the past shore or near-shore environment ('palaeoshorelines'). Palaeoshorelines above the present water level can be dated using radiometric or luminescence dating techniques to estimate the timing at which they were last active. Combined with elevation data and knowledge of basin morphometry - and if necessary corrected for post-depositional deformation that might occur through tectonic vertical displacement (e.g., Garcin et al., 2009) or isostatic adjustments of the lithosphere (e.g., Chen and Maloof, 2017) - they allow for a direct, quantitative reconstruction of water level and lake hydrology at their time of formation. Palaeoshorelines represent discrete, rather than continuous, recordings of lake-level history as they are often only deposited and preserved under specific hydrological conditions such as water-level stasis. As such, they only provide snapshots of past hydrological states. Palaeoshoreline records tend to dominate the palaeolimnological record in semi-arid to arid regions, where the climate regime necessary to maintain steady state lake-full conditions deviates most strongly from present-day climate conditions (Bowler, 1986; Burrough and Thomas, 2009).

The second source of evidence is derived from the lakebed, where the progressive deposition of sediments results in sequences representative of the character of the overlying water column through time. Such stratigraphies can be retrieved as sediment cores or as outcropping sections of sedimentary landforms above the modern water surface. Lakebed archives can be (but are not necessarily) uninterrupted deposits and thus provide a continuous time series of past lake status. Absolute reconstructions of water depth can be made from lake-bed records using sequences of cores to trace the limit of lacustrine deposition through time (e.g., Digerfeldt, 1965; Schneider and Tobolski, 1985; Winkler et al., 1986; Almqvist-Jacobsen, 1995; Shuman et al., 2009) but the procedure is timeconsuming. Generally lake-bed records only provide indirect information of relative changes in lake status approximated through sensors of water depth such as sedimentological characteristics or floral and faunal community composition. For these reasons, lake-level reconstructions derived from lakebed archives tend to be continuous but qualitative in nature.

Reconstructing lake status and associated climatic change from sedimentology and geomorphology can be challenging for several reasons (e.g., Gasse, 2000; Holmes and Hoelzmann, 2017): 
1. Like all natural palaeoenvironmental archives, the chronological control on lake records is dependent on the dating method applied. Apart from lakes containing annually varved sediments, dating of lacustrine deposits relies mostly on radiometric techniques with varying precision.

2. Lake-status archives can be incomplete and low stands are often underrepresented. In sedimentological records, low water levels or dry stands can inhibit deposition and even remove previously deposited sediments, thus creating stratigraphic hiatuses or unconformities. Similarly, palaeoshorelines above a lakebed only reflect instances where water level was higher than today, and prolonged high stands can erode previously formed shoreline structures thereby eliminating evidence for older episodes of lower water level (Burrough and Thomas, 2009).

3. The information about lake-status changes tends to decrease further back in time, which can be partly explained by practical fieldwork constraints (i.e., coring older deposits is technically challenging and costly) but also reflects difficulties of obtaining records after lake desiccation because of compaction, pedogenesis and/or mineralisation of the lakebed (e.g., Stager et al., 2002; De Cort et al., 2018). Lake coring is therefore often restricted to the time window following the most recent dry stand. The result is that lake-status data is often skewed towards recent periods of higher water level, which have a higher probability of being recorded than periods of greater age and/or lower lake status.

4. The sensitivity of lake level to climate is site-specific, as factors such as physical and ecological catchment characteristics and groundwater inflow or outflow can affect the amplitude and timing of lake response to variability in P-E (Vassiljev et al. 1998). Different archives also show different levels of sensitivity to lake-status changes, which may differ between indicators but also be non-stationary through both space and time for the same indicator (Juggins, 2013).

5. Lake-status changes can also be driven by non-climatic factors, such as gradual basin infilling, basin deformation (e.g. by tectonism or volcanism) or sea-level change. These processes can mask or modify the climate signal preserved in sedimentary or geomorphic archives.

Lakes vary widely in their climate sensitivity. Most lakes act as low-pass filters that mainly respond to lowerfrequency climate variability (Mason et al., 1994; Liu and Schwartz, 2014). Catchment size and morphometry, as well as relative groundwater flux, are major factors in determining the sensitivity of lake level to climate change (Vassiljev et al. 1998; Burrough and Thomas, 2009; Olaka et al., 2010). The time needed for a lake to return to equilibrium creates a lagged response which usually varies from months to a few years (Yi and Zhang, 2015) but can take multiple millennia in extremely large catchments (Singarayer et al., 2019).

\section{The new relational lake-status database}

This section describes the principles behind the construction of the new database, as applied to the ESA sites used in our case study (see section 5).

3.1 Data selection

Studies containing data on past lake-status change were included in the database if they fulfilled the following criteria:

1. Data and publications were peer-reviewed; 
2. Chronological data was available to anchor past lake variability in time (e.g., radiometric dating, reliable historical accounts or instrumental records);

3. Evidence indicates that lake-level changes were primarily driven by climate and were interpreted as such in the original literature. Sites or sections of individual records where changes in lake level were demonstrably non-climatic in origin (e.g., direct influence of sea-level changes, volcanism, basin infilling or anthropogenic activities) were excluded to avoid mixing environmental signals;

4. The palaeoenvironmental evidence reflected changes in lake level, depth, volume and/or area rather than other hydrological variables such as precipitation, runoff, or moisture source. Interpretations from the original literature were followed in this matter, unless competing evidence (e.g., from contradictory studies) demanded otherwise.

3.2 Compilation and revision of chronological information

A wide range of approaches for age-model construction were used in the original literature, so we built standardised chronologies for all records. Radiocarbon dates were recalibrated using IntCal13 for Northern Hemisphere sites (Reimer et al., 2013) and SHCal13 for Southern Hemisphere sites (Hogg et al., 2013). Agedepth models for sediment profiles were reconstructed using the Bayesian age-depth modelling software Bacon in R (Blaauw and Christen, 2011; R Core Team, 2020). Core-top ages were included in the age model when intact recovery of the surface sediment was reported, in which case the core top was assumed to correspond to the time of sampling. The specifics of all the age-depth models, such as the exclusion of anomalous outlying dates, the excision of event deposits, the inclusion of sediment hiatuses, and the settings of the Bacon run were adjusted on an $a d$-hoc basis for each individual sequence to ensure the most reliable results and with the objective of staying as close as possible to interpretations in the original literature.

The discrete nature of palaeoshorelines means that calibrated ages obtained from them were used directly as a shoreline age, except in the case where multiple shoreline dates overlapped within their uncertainty ranges to such a degree that they could be interpreted as representing a single continuous time interval for a specific lake status.

New chronologies were not created for sites where i) the original chronological data was (partly) unavailable but the site was considered fundamental for regional reconstruction, or ii) where the published age model was already created using Bacon with the appropriate calibration curve. Original ${ }^{14} \mathrm{C}$ measurements and associated information, as well as data from other geochronological techniques, were retained in the database to enable future updates.

\subsection{Construction of consensus lake-status histories}

Many lines of evidence only provide indirect evidence of past lake status. Thus, assumptions on the relationship between such proxies and lake level are often required to reconstruct lake status. Our standard approach was to combine all available sources of information on the assumption that if several lines of evidence point to a change in water depth or area, this consensus is real (Harrison et al., 1991; Harrison and Digerfeldt, 1993). For every site, the information on past changes in lake status was combined with the revised chronologies to produce sequences of lake-status episodes. Each episode is defined by i) a best-estimate of the start and end age, each with their associated $2-\sigma$ credible intervals, taken from individual/clustered ages from discontinuous archives (Fig. 1a) or from the reconstructed age-depth models of sediment cores (Fig. 1b); and ii) a relative qualitative lake-status class 
represented by a positive integer, in which a higher status (higher number) signifies a higher relative lake level, volume or surface area ( 1 being the lowest status documented and not necessarily meaning drystand; Fig. 1). The weighted mean of the probability distribution produced by the Bacon model, or in the case of palaeoshorelines, of the single defining chronological point, was taken as the best estimate of the 'true' age.

There is no upper limit to the number of different lake-status classes assigned to a lake, as this depends on the available lines of evidence and their sensitivity to lake-status change, the resolution of the available information and the total time span of the archive. The ranking is specific to each lake and status classes cannot be directly compared between lakes. In general, the original authors' interpretation was followed unless there were contrasting conclusions published in the literature. When the status at a particular time relative to other periods in a lake's history was ambiguous, lower and upper limits on the possible lake status class were defined. This occurred when status was based on ambiguous data interpretation, or when several archives were used that do not overlap sufficiently in time or type of evidence so that comparison of status in different periods of a lake's history was not straightforward.

Assignment of lake-status classes to lakebed sediments and palaeoshorelines was challenging in different ways. The density of palaeoshoreline dates was often insufficient to create continuous reconstructions. Additional assumptions were often required concerning the duration of events represented by features dated by only one or a few ages. The same was true for other discontinuous records such as non-shoreline geomorphological features or archaeological artefacts. With such 'snapshot' information, event duration had to be estimated conservatively, informed by the nature of the deposit and the sensitivity of the basin to hydrological changes. For example, raised beaches may be assigned shorter durations (on the order of years) than thick carbonate deposits that accumulated in the littoral zone over multiple decades or centuries. Similarly, some lake basins are well buffered against shortterm water-level fluctuations whereas others exhibit significant variability on (sub-)annual time scales, depending on basin characteristics such as morphometry, hydrography, and vegetation.

\subsection{Database structure and content}

Data on site characteristics, chronology and lake-status history was assembled into 9 tables, which were combined into a relational database and exported as a SQLite3 file (Fig. 2, SI).

Lakes - This table contains a unique site identifier, site name, coordinates and basic information on present hydrology and morphometry.

Contributors - This table includes the name and ORCID of the researcher who contributed the site history to the database, and the date (month/year) when the data were included in the database.

Alternative Names - This table links the site identifier with alternative site names used in the literature.

Refs - This table contains all the references used to compile the database.

Dating - This table contains the original individual dates as well as the outcome of their reanalysis as part of the newly generated chronologies.

Coding Basis - This table contains the site-specific definitions of all status classes. 
Coding Source - This table lists which lake-status indicators were available in the consulted literature, and which of these were used in the consensus lake-status reconstruction.

Lake Size - This table provides information on absolute water depth or lake-level elevation as recorded by geomorphological features. Best estimates of the mean, lower and upper still-water bound of each shoreline, and corresponding estimates and uncertainties of lake surface area and lake volume, are given if available from the original literature.

Coding - This table contains the lake-status histories. For each site, a sequence of episodes is defined. Each of these episodes is defined by a best-estimate start and end age, together with their associated $2 \sigma$ uncertainties, and by a best estimate, a minimum and a maximum value for lake status. The Coding table also links lake-status episodes to corresponding quantitative information, if available in the Lake Size table.

A number of additional tables is used to store lists of accepted values for specific fields or to link the different data tables together (Fig. 2, see Data availability).

\section{Analytical approach}

Integrating temporal and lake-status uncertainties allows for the extraction of robust spatiotemporal palaeoclimatic trends from data (e.g., Breitenbach et al. 2012; Anchukaitis and Tierney, 2013; Chevalier and Chase 2015). Here, we designed a specific Monte-Carlo (MC) framework to iteratively sample the lake-status histories, taking account of their uncertainties in chronology and lake status, to produce a large number of possible historical scenarios (section 4.1). These randomised iterations were subsequently used to extract the principal spatiotemporal modes of variability (section 4.2). A flowchart of this analytical approach is shown in Fig. 3.

4.1 Monte-Carlo sampling of time- and status-uncertain lake histories

Our MC algorithm iteratively sampled the Coding table to produce a large number of variants of each lake's status history; in our application (see section 5), we used 10,000 iterations. In each iteration, uncertainty ranges of start and end ages of subsequent status episodes were sampled unidirectionally through time to conserve the chronological sequence of defined episodes. The outcome of the sampling of a given time point (i.e. the start or end of a certain status episode) was thus constrained by the uncertainty defined for that point and by the result of the priorly sampled point. To avoid biasing the sampled records either towards younger or towards older ages which can happen especially for sequences of relatively short episodes with highly overlapping temporal uncertainty ranges - the sampling was performed by randomly moving either forward or backward in time. This means that for any lake, roughly half of the iterations sampled the coding table in an old-to-young sequence and the other half of the iterations sampled the coding table starting at the youngest and ending at the oldest episode. Similar to the sampling of the start and end dates of each episode, the status class was also sampled from its uncertainty range but without being constrained by the priorly sampled point, since we assumed that status class is independent between episodes.

Although the distribution of estimated ages produced by radiocarbon calibration or Bayesian age-depth modelling are generally not symmetric or even unimodal, only the model weighted means and upper and lower $95 \%$ confidence intervals are used to define the sequence of episodes that make up a lake's history in the database. Similarly, probability distributions of status classes are also not normally distributed and may be highly 
asymmetrical (see Fig. 1c). To cope with the asymmetrical nature of age uncertainties, the MC algorithm samples start and end ages of status episodes following a probability density function defined by a split-normal distribution, also known as a two-piece normal distribution. The mode of the split-normal distribution is equal to the best estimate of that age (Fig. 1c) and the left and right standard deviations $(1 \sigma)$ of the distribution are derived from the lower and upper limit of the $2 \sigma$ range as defined in the coding table. Uncertain status classes were set to follow a triangular probability density function, peaking at best-estimate values and linearly decreasing towards 0 at values of minimum-1 and maximum+1, which precludes obtaining values outside of the defined minimum-tomaximum range (Fig. 1c). The split-normal (for ages) and triangular (for status class) distributions are scaled to ensure that their cumulated probabilities sum to 1 .

\subsection{Recursively-Subtracted Empirical Orthogonal Function analysis}

To extract regional palaeoclimatic trends, MC-sampled lake-history variants were generated for a set of lakes of interest. These histories were then analysed using Empirical Orthogonal Functions (EOFs), which decompose data of high spatiotemporal dimensionality into its dominant spatiotemporal features of variability. RecursivelySubtracted Empirical Orthogonal Function (RSEOF) analysis is a specific case of EOF analysis that is able to deal with data sets with high proportions of missing values (Taylor et al., 2013), as can be the case with lake-status data. All MC-produced lake histories were interpolated to a common time scale with regular spacing. In our proofof-concept study using African lakes (see Section 5), a time step of 5 years was employed. Time series were centred and scaled to a mean of 0 and a standard deviation of 1 prior to the analysis. A reference RSEOF was also calculated for the scenario where all ages and statuses of included sites were assumed at their best-estimate value. The result was an ensemble of 10,000 (MC-generated) + 1 (best-estimate) sets of principal components (PCs), each summarizing the dominant spatiotemporal modes of variability in their corresponding set of lake-status histories. By construction, the sign of each eigenvector is arbitrary (Legendre \& Legendre, 2012). To homogenise the sign of corresponding eigenvectors across all RSEOF iterations, each PC was multiplied by -1 if this resulted in a reduction of its distance to the corresponding $\mathrm{PC}$ of the set of best-estimate lake-status histories, i.e. the sign and direction of each eigenvector was aligned with the sign and direction of the eigenvector of the reference RSEOF. For each RSEOF iteration, unicity of EOF modes was assessed using North's Rule of Thumb, which determines which eigenvectors are distinct from their nearest neighbour (North, 1982). RSEOF analyses were carried out using the R package sinkr (Taylor, 2017; R Core Team, 2020).

\section{Case study: lake-status history in eastern and southern Africa}

\subsection{Regional setting}

Our study area - eastern and southern Africa (ESA) - is delimited by the Sahel to the north and by the Congo Basin and the Angolan highlands to the west (Fig. 4) and encompasses different climatic zones (Gasse et al., 2008; Burrough and Thomas, 2013). Tropical East Africa and Madagascar mainly receive monsoonal rainfall from the Indian Ocean associated with the yearly migration of the tropical rain belt, although Atlantic moisture can also significantly contribute in western areas (Nicholson, 2017; 2018). In southern Africa, the strength of the monsoon decreases with distance from the Indian Ocean, grading from the subtropical grasslands and savannas in the east into the arid Kalahari over the southern African plateau and finally into the hyper-arid Namib Desert along the west coast. This pattern is additionally influenced by the cold Benguela current in the Atlantic, further depriving 
the Namib of rain. The southern and southwestern coasts of South Africa are dominated by a Mediterranean climate, where winter rains prevail (Tyson and Preston-White 2000).

Lake sediments are the dominant source of palaeoenvironmental and palaeoclimatic reconstructions for East Africa (Verschuren, 2003). Tectonic activity and faulting associated with the East-African Rift System (EARS) have produced a string of basins which are arranged in two distinct rift branches (Chorowicz, 2005). The western branch, or Albertine Rift, holds several large and deep freshwater lakes (Tiercelin and Lezzar, 2002). Lakes of the eastern branch, or Gregory Rift, are typically smaller, shallower and more saline (Schagerl and Renaut, 2016). Additionally, volcanic activity associated with the EARS created a number of explosion craters, many of which hold small but sometimes relatively deep lakes. High densities of these crater lakes are found for example in the Rungwe Volcanic Province of southern Tanzania (Delalande et al., 2008) and the maar crater lake districts of southwestern Uganda (Melack, 1978). Locally concentrated small lakes of glacial origin are found in the alpine zones of the highest peaks and mountain ranges of East Africa (e.g., Mahaney, 2004; Eggermont and Verschuren, 2007; Eggermont et al., 2007; Tiercelin et al., 2008).

Because of southern Africa's dry conditions; a deep covering of sand related to its cratonic origins (Haddon and McCarthy, 2005); and the restricted influence of rifting, the southern African interior has less potential for deep lakes than East Africa. Today, most lakes and wetlands are found along the coast of South Africa, where they are often under significant marine influence (Hill, 1975; Whitfield et al., 2017). Nevertheless, the subcontinental interior holds many endorheic basins of various sizes, most of which are perennially dry or hold seasonally filled playas today, but where geomorphological features provide evidence for long-lived standing water in the past.

\subsection{The ESA lake-status database}

We identified a total of 67 lakes in ESA that met the criteria defined in Sect. 3.1 (Fig. 4, Table 1). Sites from the original GLSDB were only incorporated here if they met these criteria, and their GLSDB histories were critically re-evaluated in the process. Data for these sites was sourced from 244 publications (see Supplementary Material). Their catchments were delineated using the HydroSHEDS database (Lehner et al., 2008) or, for the smallest drainage basins, by manual delineation using Google satellite imagery and Advanced Spaceborne Thermal Emission and Reflection Radiometer (ASTER) Global Digital Elevation Model (GDEM) v2 data (ASTER GDEM is a product of METI and NASA). The ESA database is available online, along with supplementary documentation for each individual site (see Data availability).

The current nature of the lakes in these basins reflects regional climate. Most basins are topographically closed today (54/67). Seasonally or perennially dry basins are disproportionately common in the interior and western portions of southern Africa, while 10 of the 13 currently overflowing lakes are located within $12^{\circ}$ of the Equator. Slightly more than half the sites (39/67) occur below $1000 \mathrm{~m}$ a.s.1., while 4/67 of sites lie above $2000 \mathrm{~m}$ asl. Most lakes have a surface area smaller than $100 \mathrm{~km}^{2}$ (50/67) while 9/67 are currently larger than $1000 \mathrm{~km}^{2}$. Catchment area ranges from $<1 \mathrm{~km}^{2}$ for the smallest crater lakes to $1,205,959 \mathrm{~km}^{2}$ for the Makgadikgadi basin (Fig. 5a). The most common sources of evidence for lake status (Table 1) are stratigraphy (used in 36/67 of all sites) and sedimentological composition of deposits (34/67), diatoms (32/67), non-shoreline geomorphology (27/67) and palaeoshorelines (21/67). Historical and/or instrumental gauge data was used for 12/67 and 8/67 of lakes, respectively. The number of defined status classes per site ranged from 2 to 15 . 


\begin{tabular}{|c|c|c|c|c|c|c|c|c|c|c|c|c|c|c|c|c|c|c|c|c|c|}
\hline \multirow[b]{2}{*}{ ID } & \multirow[b]{2}{*}{ Site name } & \multicolumn{2}{|c|}{ Coordinates } & \multirow[b]{2}{*}{$\begin{array}{l}\text { Current } \\
\text { hydrology }\end{array}$} & \multicolumn{15}{|c|}{ Lake-status proxies used } & \multirow{2}{*}{ 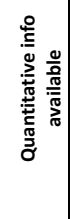 } & \multirow[b]{2}{*}{ References } \\
\hline & & Lon & Lat & & 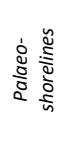 & 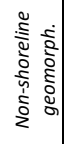 & 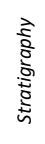 & 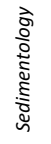 & 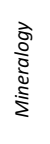 & 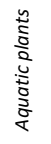 & 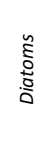 & 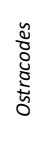 & :ू̆ & 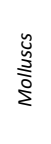 & 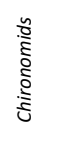 & 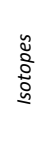 & 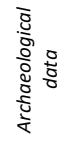 & 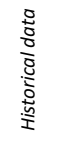 & 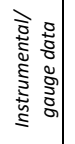 & & \\
\hline 1 & Lake Chilwa & 35.5 & -15.5 & closed & $x$ & & & & & & & & & & & & & $x$ & & $x$ & Owen and Crossley (1990); Thomas et al. (2009) \\
\hline 2 & $\begin{array}{l}\text { Lake } \\
\text { Tritrivakely }\end{array}$ & 46.92 & -19.78 & closed & & & & & $x$ & $x$ & $x$ & & & & & & & & & & $\begin{array}{l}\text { Gasse et al. (1994); Williamson et al. (1998); Gasse and } \\
\text { van Campo (1998); Gasse and van Campo (2001) }\end{array}$ \\
\hline 3 & Lake Lungué & 33.6358 & -24.7619 & closed & & & & & & & $\mathrm{x}$ & & & & & & & & & & Sitoe et al. (2017) \\
\hline 4 & Lake Cheshi & 29.75 & -9.08333 & closed & & & & & & & $x$ & & & & & & & & & & Stager (1988) \\
\hline 5 & Ishiba Ngandu & 31.741 & -11.235 & open & & & $x$ & & & & $\mathrm{x}$ & & & & & & & & & & Livingstone (1971); Haberyan (2018) \\
\hline 6 & $\begin{array}{l}\text { Lake } \\
\text { Nhauhache }\end{array}$ & 35.2947 & -21.9807 & closed & & & & & & & $\mathrm{x}$ & & & & & & & & & & Holmgren et al. (2012) \\
\hline 7 & Lake Mapimbi & 31.28 & -22.4025 & closed & & & & & & & $\mathrm{x}$ & & & & & & & & & & Gillson and Ekblom (2009); Ekblom et al. (2012) \\
\hline 8 & Lake Sibaya & 32.6121 & -27.3441 & closed & & & & & & & $\mathrm{x}$ & & & & & & & & & & Neumann et al. (2008); Stager et al. (2013) \\
\hline 9 & Princess Vlei & 18.483 & -34.047 & $\begin{array}{l}\text { open, } \\
\text { significant } \\
\text { groundwater } \\
\text { influence } \\
\end{array}$ & & & & & & & $x$ & & & & & & & & & & Kirsten and Meadows (2016) \\
\hline 10 & Lake Chilau & 34.9486 & -23.9644 & open & & & & & & & $\mathrm{x}$ & & & & & & & & & & Norstrom et al. (2018) \\
\hline 11 & Lake Nhaucati & 35.3120 & -22.0377 & closed & & & & & & & $x$ & & & & & & & & & & Ekblom and Stabell (2008); Norstrom et al. (2018b) \\
\hline 12 & Verlorenvlei & 18.433 & -32.35 & open & & & & & & & $\mathrm{x}$ & & & & & & & & & & Kirsten et al. (2020) \\
\hline 13 & Lake Naivasha & 36.3548 & -0.7636 & $\begin{array}{l}\text { closed, } \\
\text { significant } \\
\text { groundwater } \\
\text { influence } \\
\end{array}$ & $x$ & $\mathrm{x}$ & $\mathrm{x}$ & $\mathrm{x}$ & $\mathrm{x}$ & & $x$ & $\mathrm{x}$ & & & $x$ & & & & & $x$ & $\begin{array}{l}\text { Richardson and Richardson (1972); Washbourne-Kamau } \\
\text { (1975); Richardson and Dussinger (1986); Verschuren et } \\
\text { al. (2000); ; evrschuren (2001); Bergner et al. (2003); } \\
\text { Bergner and Trauth (2004); Van der Meeren et al. (2019) }\end{array}$ \\
\hline 14 & Lake Ashenge & 39.5013 & 12.5795 & closed & & $\mathrm{x}$ & $\mathrm{x}$ & $\mathrm{x}$ & $x$ & & $x$ & & & & & $x$ & & & & & Marshall et al. (2009) \\
\hline 15 & Lake Nabugabo & 31.8995 & -0.3639 & $\begin{array}{l}\text { open, } \\
\text { significant } \\
\text { groundwater } \\
\text { influence } \\
\end{array}$ & $x$ & & & $\mathrm{x}$ & $\mathrm{x}$ & & & & & & & & & & & & Stuiver et al. (1960); Stager et al. (2005) \\
\hline 16 & Lake Chibwera & 30.1419 & -0.1546 & closed & & & $\mathrm{x}$ & $\mathrm{x}$ & $x$ & & & & & & & & & & & & Bessems et al. (2008) \\
\hline 17 & Lake Emakat & 35.8409 & -2.9125 & closed & & & $\mathrm{x}$ & $\mathrm{x}$ & & $\mathrm{x}$ & $\mathrm{x}$ & $\mathrm{x}$ & & & $\mathrm{x}$ & & & & & & $\begin{array}{l}\begin{array}{l}\text { Muzuka et al. (2004); Ryner et al. (2007); Ryner et al. } \\
\text { (2008) }\end{array}\end{array}$ \\
\hline 18 & Lake Victoria & 33 & -1 & $\begin{array}{l}\text { open, } \\
\text { artifically } \\
\text { controlled }\end{array}$ & $x$ & & $\mathrm{x}$ & & & & $\mathrm{x}$ & & & & & & & & & $x$ & $\begin{array}{l}\text { Stuiver et al. (1960); Kendall (1969); Stager (1984); } \\
\text { Stagere retal. (1986); Sene and Plinston (1994); ohnson } \\
\text { et al. (1996); Stager et al. (1997); Johnson et al. (1998); } \\
\text { Johnson et al. (2000); Beuning et al. (2002); Stager et al. } \\
\text { (2002); Stagere tal. (2003); Stager et al. (2005); Stager } \\
\text { et al. (2005b); }\end{array}$ \\
\hline 19 & Suguta & 36.5 & 2.05 & $\begin{array}{l}\text { closed, } \\
\text { seasonally } \\
\text { filled }\end{array}$ & $\mathrm{x}$ & $\mathrm{x}$ & $\mathrm{x}$ & $\mathrm{x}$ & & & & & & $\mathrm{x}$ & & & & & & $\mathrm{x}$ & $\begin{array}{l}\text { Truckle (1976); Garcin et al. (2009); Junginger et al. } \\
\text { (2014) }\end{array}$ \\
\hline
\end{tabular}




\begin{tabular}{|c|c|c|c|c|c|c|c|c|c|c|c|c|c|c|c|c|c|c|c|}
\hline 20 & Lake Challa & 37.7 & -3.317 & closed & & $x$ & $x$ & $x$ & & & & & & & & & & & $\begin{array}{l}\text { Payne (1970); Verschuren et al. (2009); Moernaut et al. } \\
\text { (2010); Wolff et al. (2011); Blaauw et al. (2011) }\end{array}$ \\
\hline 21 & $\begin{array}{l}\text { Nakuru- } \\
\text { Elmenteita }\end{array}$ & 36.17 & -0.4 & closed & $x$ & $x$ & & $x$ & & & $x$ & $x$ & & & & & $\mathrm{x}$ & $x$ & $\begin{array}{l}\text { Washbourn-Kamau (1971); Butzer et al. (1972); Vareschi } \\
\text { (1982); Cohen et al. (1983); Richardson and Dussinger } \\
\text { (1986); Dühnforth et al. (2006); De Cort et al. (2013) }\end{array}$ \\
\hline 22 & Kitagata & 29.9755 & -0.0637 & closed & & & $\mathrm{x}$ & $\mathrm{x}$ & $\mathrm{x}$ & & & & & & & & & & Russell et al. (2007) \\
\hline 23 & Kibengo & 30.1783 & -0.0817 & open & & & $\mathrm{x}$ & $\mathrm{x}$ & $\mathrm{x}$ & & & & & & & & & & Russell et al. (2007) \\
\hline 24 & Lake Hayq & 39.7167 & 11.35 & closed & $\mathrm{x}$ & $\mathrm{x}$ & $x$ & & & & & & & & & $\mathrm{x}$ & & $x$ & $\begin{array}{l}\text { Lamb et al. (2007); Ghinassi et al. (2012); Ghinassi et al. } \\
\text { (2015) }\end{array}$ \\
\hline 25 & Lake Kasenda & 30.29 & 0.4322 & closed & & & $x$ & $\mathrm{x}$ & $\mathrm{x}$ & & & & & & $x$ & & & & $\begin{array}{l}\text { Ssemmanda et al. (2005); Bessems (2007); Ryves et al. } \\
\text { (2011); Mills and Ryves (2012) }\end{array}$ \\
\hline 26 & $\begin{array}{l}\text { Lake } \\
\text { Nyamogusingiri }\end{array}$ & 30.013 & -0.2846 & closed & & & $x$ & & & & $x$ & & & & & & & & Mills et al. (2014) \\
\hline 27 & $\begin{array}{l}\text { Lake } \\
\text { Kyasanduka }\end{array}$ & 30.0502 & -0.2898 & closed & & & $\mathrm{x}$ & & & & $x$ & & & & & & & & Mills et al. (2014) \\
\hline 28 & Lake Tana & 37.25 & 12 & open & & & $x$ & $\mathrm{x}$ & & & $x$ & & & & & & & & $\begin{array}{l}\text { Lamb et al. (2baringo007b); Marshall et al. (2011); Costa } \\
\text { et al. (2014) }\end{array}$ \\
\hline 29 & Lake Abhe & 41.8 & 11.2 & closed & $\mathrm{x}$ & $\mathrm{x}$ & $\mathrm{x}$ & $\mathrm{x}$ & $\mathrm{x}$ & & $\mathrm{x}$ & & & & & & & $\mathrm{x}$ & Gasse (1977); Gasse and Street (1978) \\
\hline 30 & $\begin{array}{l}\text { Lake Abiyata } \\
\text { (Ziway-Shala) }\end{array}$ & 38.6 & 7.6 & closed & $x$ & $x$ & $x$ & $x$ & $x$ & & $x$ & & & & & & $x$ & $x$ & $\begin{array}{l}\begin{array}{l}\text { Gasse and Street (1978); Gillespie et al. (1983); Chalié } \\
\text { and Gasse (2002); Legesse et al. (2002) }\end{array} \\
\end{array}$ \\
\hline 31 & Lake Duluti & 36.7833 & -3.3833 & closed & & & & & & & $x$ & & & & & & & & öberg et al. (2012); Öberg et al. (2013) \\
\hline 32 & Lake Tilo & 38.0958 & 7.0625 & closed & & & $\mathrm{x}$ & $x$ & $x$ & & $x$ & & & & $x$ & & & & $\begin{array}{l}\text { Telford and Lamb (1999); Lamb et al. (2000); Lamb et al. } \\
\text { (2004); Lamb et al. (2005) }\end{array}$ \\
\hline 33 & Lake Sonachi & 36.262 & -0.782 & closed & & & $\mathrm{x}$ & $\mathrm{x}$ & $x$ & & & & & & & & & & $\begin{array}{l}\text { Damnati and Taieb (1996); Verschuren (1999); } \\
\text { Verschuren et al. (1999) }\end{array}$ \\
\hline 34 & Lake Albert & 31 & 1.5 & open & & & $\mathrm{x}$ & $x$ & $x$ & $x$ & $x$ & & $x$ & & & & & & $\begin{array}{l}\text { Hecky and Degens (1973); Harvey (1976); Stoffers and } \\
\text { Singer (1979); Beuning et al. (1997); Lehman (1998) }\end{array}$ \\
\hline 35 & Lake Turkana & 36 & 3.5 & closed & $x$ & $x$ & $x$ & $x$ & $x$ & & & & & $x$ & & $x$ & $x$ & & 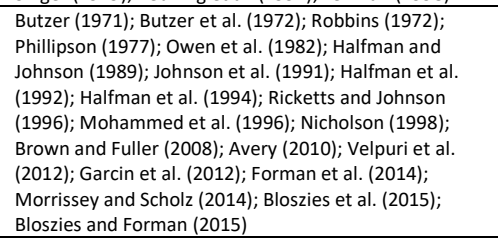 \\
\hline 36 & Magadi-Natron & 36.04 & -2.12 & $\begin{array}{l}\text { closed, } \\
\text { seasonally } \\
\text { filled }\end{array}$ & & & & $x$ & $x$ & & $x$ & & & & & $x$ & & $x$ & $\begin{array}{l}\text { Butzer et al. (1972); Hillaire-Marcel et al. (1986); } \\
\text { Hillaire-Marcel and Casanova (1987); Barker et al. } \\
\text { (1990); Taieb et al. (1991); Roberts et al. (1993); } \\
\text { Williamson et all. (1993); Damnati and Taieb (1995); } \\
\text { Hughes (2008) }\end{array}$ \\
\hline 37 & Lake Edward & 29.5833 & -0.4167 & open & & & $x$ & $x$ & $x$ & & & & & & & & & & $\begin{array}{l}\text { Bishop (1969); Brooks and Smith (1987); Musisi (1991); } \\
\text { de Heinzelin and Verniers (1996); Laerdal et al. (2002); } \\
\text { Russell et al. (2003); Russell and Johnson (2005); Russell } \\
\text { and Johnson (2007) }\end{array}$ \\
\hline 38 & Lake Hora & 41.95 & 9.43 & closed & $\mathrm{x}$ & & & & & & & & & & & & & $\mathrm{x}$ & Williams et al. (1977) \\
\hline 39 & Lake Besaka & 39.87 & 8.86 & $\begin{array}{l}\text { closed, } \\
\text { significant } \\
\text { groundwater } \\
\text { influence } \\
\end{array}$ & & $x$ & $x$ & & & & & & & & & & & & Williams et al. (1977); Williams et al. (1981) \\
\hline 40 & Loboi Swamp & 36.05 & 0.3667 & open, bog & & & $x$ & $x$ & $x$ & & $x$ & & & & $x$ & & & & Ashley et al. (2004); Driese et al. (2004) \\
\hline 41 & Lake Rukwa & 32.717 & -8.417 & closed & $x$ & & $x$ & $x$ & $x$ & & $x$ & & & & & $\mathrm{x}$ & $x$ & $\mathrm{x}$ & $\begin{array}{l}\text { Clark et al. (1970); Haberyan (1987); Talbot and } \\
\text { Livingstone (1989); Delvaux et al. (1998); Nicholson }\end{array}$ \\
\hline
\end{tabular}




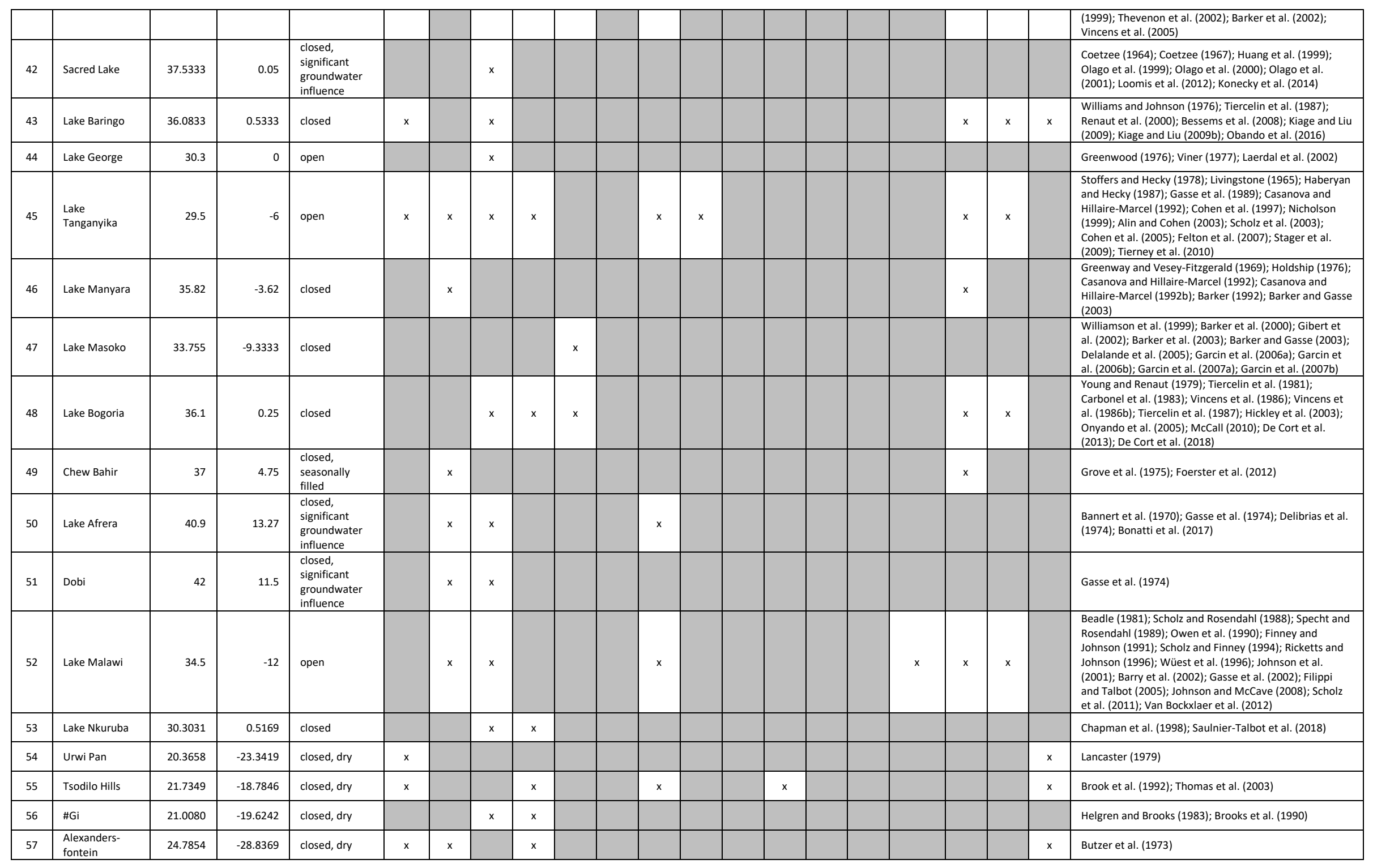




\begin{tabular}{|c|c|c|c|c|c|c|c|c|c|c|c|c|c|c|}
\hline 58 & Ngami & 22.7315 & -20.4983 & $\begin{array}{l}\text { closed, } \\
\text { seasonally } \\
\text { filled }\end{array}$ & $\mathrm{x}$ & $x$ & & & & & $\mathrm{x}$ & $\mathrm{x}$ & $x$ & $\begin{array}{l}\text { Shaw (1985); Shaw et al. (2003); Huntsman-Mapila et al. } \\
\text { (2006); Burrough et al. (2007) }\end{array}$ \\
\hline 59 & Makgadikgadi & 25.4883 & -20.7430 & closed, dry & $\mathrm{x}$ & $\mathrm{x}$ & & & & $\mathrm{x}$ & $x$ & & $\mathrm{x}$ & $\begin{array}{l}\text { Cooke and Verstappen (1984); Shaw et al. (1997); } \\
\text { Ringrose et al. (2005); Burrough et al. (2009); Schmidt et } \\
\text { al. (2017) }\end{array}$ \\
\hline 60 & Mababe & 24.1585 & -18.8482 & closed, dry & $\mathrm{x}$ & $\mathrm{x}$ & & & & & $x$ & & $x$ & $\begin{array}{l}\text { Shaw (1985); Shaw and Cooke (1986); Shaw and Thomas } \\
\text { (1988); Shaw and Thomas (1993); Burrough and Thomas } \\
\text { (2008) }\end{array}$ \\
\hline 61 & Etosha & 16.3016 & -18.8056 & closed, dry & $\mathrm{x}$ & $\mathrm{x}$ & & & & & & & $\mathrm{x}$ & $\begin{array}{l}\text { Buch and Zoller (1992); Brook et al. (2007); Brook et al. } \\
\text { (2011); Brook et al. (2013); Hipondoka et al. (2014) }\end{array}$ \\
\hline 62 & Tsondab & 15.1606 & -23.8850 & closed, dry & & $\mathrm{x}$ & $x$ & $\mathrm{x}$ & & & & & & $\begin{array}{l}\text { Vogel and Visser (1981); Teller and Lancaster (1986); } \\
\text { Teller et al. (1990); Stone et al. (2010) }\end{array}$ \\
\hline 63 & $\begin{array}{l}\text { Branddam-East } \\
\text { Pan }\end{array}$ & 18.8419 & -26.3594 & closed, dry & & $\mathrm{x}$ & & $\mathrm{x}$ & $\mathrm{x}$ & & & & & Schüller et al. (2018) \\
\hline 64 & Omongwa Pan & 19.3704 & -23.7064 & closed, dry & & $\mathrm{x}$ & & $\mathrm{x}$ & $\mathrm{x}$ & & & & & Schüller et al. (2018) \\
\hline 65 & Kathu Pan & 23.0083 & -27.6619 & closed, dry & & $\mathrm{x}$ & & $\mathrm{x}$ & & & & & & Beaumont et al. (1984) \\
\hline 66 & Lebatse Pan & 23.8386 & -23.8830 & closed, dry & & $\mathrm{x}$ & & $x$ & & & & & & Holmgren and Shaw (1997) \\
\hline 67 & Witpan & 20.15 & -26.6666 & closed, dry & & $\mathrm{x}$ & & $\mathrm{x}$ & & & & & & Holmgren and Shaw (1997); Telfer et al. (2009) \\
\hline
\end{tabular}

Table 1 Summary of sites incorporated in our ESA lake-status database and sources of evidence for constructing their lake-status history. For full references, see the Supplementary Material of the final version of this manuscript. 
The chronological data is summarised in Fig. 6. The database contains 1856 published chronological points, of which $72 \%$ are radiocarbon dates. A significant portion of radiocarbon dates (29\%) had not been calibrated in the original publication. Optically stimulated luminescence (14\% of the total), U/Th (1\%) and thermoluminescence (1\%) dates were almost exclusively obtained from non-core geomorphic features. Only 1460 chronological points (79\% of the total) were used to establish the updated chronologies. Excluded dates either were demonstrated or suspected to be erroneous, or were from archives that were not used in the final consensus lake-status history. Chronologies were reconstructed for all except 2 sites where chronological data were unavailable and 4 sites where the published age model was already created using Bacon with appropriate radiocarbon calibration. Only 3 sites have lake-status information at 50,000 cal yr BP. This number increases to 16 at 20,000 cal yr BP, 27 at $10,000 \mathrm{cal} y r$ BP, and 36 at $1000 \mathrm{cal} \mathrm{yr} \mathrm{BP.} \mathrm{The} \mathrm{average} \mathrm{resolution} \mathrm{of} \mathrm{revised} \mathrm{chronologies} \mathrm{over} \mathrm{the} \mathrm{last} \mathrm{20,000}$ years, here defined as the number of used dates divided by the total duration of the record, is 4.1 (min 0.03 , max 38.4) dates per 1000 years. For sites that go back to at least 20,000 cal yr BP, average dating resolution over the period 20,000 cal yr BP to $2020 \mathrm{CE}$ is $1.3(\min 0.0, \max 8.3, \mathrm{n}=26)$ dates per 1000 years. Similarly, over the period 1000 cal yr BP to CE 2020 it is $5.3(\min 0.0, \max 57, \mathrm{n}=58)$ dates per 1000 years.

The number of informative sites decreases with age (Figs. 5b, 7, cf. Section 2). The varying availability of palaeolimnological records through time in ESA is partly the result of the lake-level changes these records document. For example, the steep decrease in the number of sites with lake-status information before ca. $2000 \mathrm{cal}$ yr BP (Fig. 7) can be traced at least in part to the many relatively small and shallow lakes in East Africa that desiccate relatively regularly and therefore do not contain archives older than a couple of millennia (Verschuren, 2003). This bias in archive development by local climate is inherent to palaeolimnology in arid to semi-arid climate zones.

Although long histories are available from catchments of all sizes, there is a positive correlation between catchment size and the age of the oldest available information on lake status (Fig. 5a). Large catchments are generally associated with a higher variety in depositional environments, producing a diversity in palaeolimnological evidence that is more likely to survive for extended periods of time. Larger basins may also get more attention from the scientific community, resulting in a higher likelihood of deep-drilling campaigns or intensive geomorphological surveys. The largest catchments in the database are of such dimensions that their water levels are no longer driven solely by local climate but follow an integrated response to distinct climate patterns within several climate zones (e.g., Burrough et al., 2009). On average more status classes were defined for long histories from large catchments (Fig. 5a). This might reflect a higher sensitivity to moisture-balance change that comes with large, climatologically and ecologically diverse catchments and higher catchment to lake area ratios (Street, 1980; Olaka et al., 2010), but it is also likely that longer records contain evidence of higheramplitude climate variability justifying more status classes. Shorter records typically have more status classes defined per unit of time (not shown) and the number of defined status episodes increases closer to the present (Fig. 5b), reflecting the different resolutions typically employed when studying archives of different length.

\subsection{Application of joint MC-RSEOF analysis}

We applied our joint MC-RSEOF framework (Fig. 3) to extract the dominant histories of the studied lakes across ESA during the past 20,000 years. Very few sites completely cover this time window: some sites have continuous 
histories but do not extend back to 20,000 years, others' histories are fragmentary across that time window. The RSEOF method allows for incomplete datasets, but the meaning of the PCs is directly related to the amount of information available in the system. Temporal coverage determines how complete a certain lake-status history is over the studied period, while the number of status classes reflects the sensitivity of a lake to undergo significant change and to record that change. The number of included lakes is also likely to have an influence on the PCs.

To determine to what extent the outcomes of our analyses are affected by temporal coverage, sensitivity to environmental change, data resolution and the number of the included lake-status records, we investigated different combinations of these site-selection criteria. Temporal coverage of the 20,000-0 cal yr BP window was set to $10,25,33,50,75$ or $100 \%$, and the minimum required number of status episodes covering (part of) that window was set to 2 or 4 , which resulted in the number of sites meeting these criteria, and thus being retained for subsequent RSEOF analyses, varying between 7 and 45 (Fig. 8a).

\subsection{Millennial-scale lake-status variability in ESA over the last 20,000 years}

The number of non-overlapping (i.e., distinct from neighbouring) EOFs and the amount of variance explained by the first EOF modes varied as different criteria for site inclusion were employed (Fig. 8a). Within this range of experiments, best-estimate scenarios result in 0 to 2 distinct (non-overlapping with their nearest neighbour) EOFs, which increases up to 4 in a minority of MC-produced scenarios. Distinct EOFs emerge when the coverage threshold is intermediate, as low temporal coverage produces too sparsely populated covariance matrices and results in gamma amplification due to lack of information (Taylor et al., 2013), while high temporal coverage excludes too many sites from the analysis. This may also explain why the amount of variance explained by EOF1 does not change significantly when the time-coverage criterion is changed between 33 and $100 \%$, i.e. the advantage of using more complete records is balanced by the reduction in their number. The time series of EOF1 is relatively consistent across tested subsets, despite the EOFs being based on a variable number of lake sites (Fig. $8 b)$. This supports the notion that EOF1 reflects lake-status behaviour that is relatively consistent across the study region.

Fig. 9 highlights the RSEOF results for the subset of sites that cover at least 33\% of 20,000-0 cal BP and for which at least 4 status episodes were defined during this time window. The scree plot (Fig. 9b) shows eigenvalues levelling from EOF3 onward, and North's rule of thumb identifies only the first 2 EOFs as non-overlapping. The first EOF explains $40.3 \pm 3.8 \%$ of the variability in lake status across the MC ensemble of 10,000 simulations, or $43.6 \%$ in the best-estimates scenario. When interpreted as a trajectory of lake status, sites that score positively on this EOF tend to have low lake status at 20,000 cal yr BP, culminating in a minimum around c. 17,500-16,500 cal yr BP (Fig. 9c, d). Afterwards, lake status increases towards the start of the Holocene, although with a temporary reversal of this trend between c. 13,000-12,000 cal yr BP. A prolonged maximum in lake status is registered between c. 11,000-5,000 cal yr BP. After c. 4,000 cal yr BP, levels are intermediate between those of the start of the record and those of the early Holocene. All the sites that correlate positively to EOF1 are located in the EARS and Madagascar (Fig. 9a, c). Sites negatively correlated to EOF1 (i.e. showing opposite trends in lake status) are confined to interior and western southern Africa, with the exception of Lake Masoko in the southern Rift. The EOF biplot also shows the distinction between interior southern Africa and East Africa along the first axis, while homogeneous distribution among negatively scoring subregions reveals little to no spatial pattern within the EARS 
(Fig. 9a). The consistency of EOF1 across experiments with differential site selection (Fig. 8b), as well as the relatively narrow $95-\%$ uncertainty envelope that is similar to EOF1 of the best-estimate lake histories (Fig. 9d), suggest that the dominant millennial-scale lake-status patterns in ESA over the last 20,000 years are widely represented and robust against the combined influence of chronological and status uncertainties. The first EOF shows that lake status variability over the last 20,000 years is dominated by a coherent pattern of regionally opposed behaviour between the EARS and interior southern Africa.

The late-Glacial portion of EOF1 is remarkably similar to the climatic trend of the deglaciation in Africa according to transient palaeoclimate model simulations (Otto-Bliesner et al., 2014) and important palaeoclimate records from Africa (e.g., deMenocal 2000; Weldeab et al., 2007; Tierney and deMenocal 2013). Heinrich Stadial 1, which has been described as an extreme climatic event for the Afro-Asian monsoon region (Stager et al., 2011), is associated with minimum lake status across the EARS and high lake status in interior southern Africa between ca. 18,000-16,000 cal yr BP. From ca. 15,000 cal yr BP, lake-status EOF1 shows the increase of monsoonal precipitation over East Africa as a possible response to rising greenhouse-gas concentrations (Otto-Bliesner et al., 2014). This evolution is temporarily interrupted during the Younger Dryas (YD), a global event that is also captured in our EOF1 (Rasmussen et al., 2006; Carlson, 2013). With their almost uniformly positive loading on EOF1, lakes within the EARS had a high status during the early to mid-Holocene, concurrent with the widespread African Humid Period (Jolly et al., 1998; deMenocal et al., 2000; Shanahan et al., 2015). In contrast to northern Africa, where a similar early- to mid-Holocene humidity maximum was induced by the precessional expansion of the West-African monsoon (Kutzbach and Otto-Bliesner, 1982; Otto-Bliesner et al., 2014), the causes for tropical East Africa's similar moisture-balance behaviour during this episode remain unclear (Tierney et al., 2011; Liu et al., 2017; Reid et al., 2019; Wang et al., 2019).

The number of informative sites through time reflects the trends reconstructed by EOF1 (Fig. 7). The maximum of informative Kalahari sites is observed between 18,500-15,500 cal yr BP, as well as prolonged recording in the Namib between 17,000-11,000 cal yr BP, meaning that shorelines formed across the region during these times due to increased lake status. Afterwards, Holocene palaeoshorelines are less common across the interior of southern Africa, except for a short-lived increase in Kalahari sites around 6000-5500 cal yr BP. The aridification of southern-African drylands, mostly reflected in our database through absence of lake-status evidence, has been reconstructed from other data sources (Goudie and Thomas, 1986; Telfer and Thomas, 2006; Thomas, 2016, Chase et al. 2019). In contrast, the number of records from the EARS increases as lakes recovered from widespread lowstands or desiccation during HS1 (Stager et al., 2011). High numbers of sites reflect maximum positive moisture balance during the early Holocene, before a slight decrease during the mid Holocene and a final rise towards maximum numbers from ca. $4000 \mathrm{cal}$ yr BP to the present.

More caution is necessary when interpreting higher-order EOFs of uncertain time series (e.g., Anchukaitis and Tierney, 2013). While significantly different from its nearest neighbours, EOF2 has large uncertainties and a low explanatory power (Fig. 9f), explaining $19.8 \pm 1.9 \%$ of the total variance across all MC iterations, and $18.7 \%$ in the case when only best-estimate lake-status histories are used. The main difference between EOF2 and EOF1 time series is the Holocene section, where EOF2 values for the early to mid-Holocene are similar to those of the preceding millennia, and the last 4,000 years show the most negative values of the entire period (Fig. 9f). The 
uncertainty range of EOF2 is considerably wider than the uncertainty range of EOF1. While sites south of $10^{\circ} \mathrm{S}$ load positively on EOF2, there is no evident spatial pattern for the EARS (Fig. 9a, e). We were not able to identify a mechanism for this trend with such a scatter of positive and negative loadings across the EARS. However, its general trend and consistent correlation to sites across the Kalahari could support the general evolution towards drier conditions over the last 20,000 years.

The trends and events identified in ESA have been described in earlier studies based either on individual records or from syntheses of selected palaeoclimate records (e.g., Chase et al., 2010; Stager et al., 2011; Stone, 2014; Singarayer and Burrough, 2015). While this paper does not aim at exploring the causal climatological processes behind them, the coherence of our results with well-established climatic events as evident in independent records demonstrates that robust palaeoclimate trends can be identified from qualitative and discontinuous lake-status data when age-model and interpretation uncertainties are taken into account.

\section{Discussion and recommendations}

Any collection of palaeoenvironmental data is confronted with what can be called a 'synthesis dilemma': the choice between targeting a low number of high-quality records at the expense of spatial and/or temporal coverage, or including as much data as possible, thereby increasing the internal noise of the data compilation due to lower average data quality. For the former, the curation of records often requires subjective interpretations of what is considered 'high-quality', which is not without its own limitations. The lake-status synthesis method presented in this paper adopts a more conservative approach and includes as many lakes as possible. Lake-status histories are often fragmentary and of variable temporal resolution, making them challenging to incorporate in palaeoenvironmental syntheses that often focus on selected archives or records of higher continuity and/or resolution (e.g., Tierney et al., 2013; McKay and Kaufman, 2014; Steiger et al., 2018; Atsawawaranunt et al., 2019). Our ESA case study nevertheless demonstrates that robust palaeoclimate patterns can still be extracted when the proxy and dating uncertainties are taken into account, even from collections of lake-status histories containing highly discontinuous and uncertain time series. Most interestingly, our final product derived from our MC-RSEOF approach has relatively narrow uncertainties - compared to the uncertainties of the composing records (see Fig. 1), thus highlighting its capacity to extract reliable signals, even from noisy data.

Uncertainty in relative lake status can have different causes, such as poorly documented sedimentation processes, uncertain translation of biological indicators to environmental change, and uncertainties comparing environmental indicators, especially when different indicators are used for different parts of a record. Consideration of uncertainty in the interpretation of a record is rarely taken into account in palaeoclimate-data syntheses, but can be important (e.g., Lohmann et al., 2013). The definition of minimum and maximum possible lake status, which together with the best estimate describe a triangular probability density function, is a practical solution to such challenges.

The incorporation of temporal uncertainty is crucial to assess past environmental variability (McKay and Kaufman, 2014). For example, Comas-Bru et al. (2019) explored the influence of chronological uncertainty in matching speleothem isotope data to climate model simulations over time windows of variable length. According to Anchukaitis and Tierney (2013), the instability introduced by temporal uncertainty is one of the main limits to recovering higher-order modes of variability from $\mathrm{MC}$-sampled uncertain time series. When using our algorithm 
to study a fixed-boundary time window, chronological uncertainty not only affects the temporal data distribution but also the number of sites providing those data. In practice, the number of sites meeting a certain temporalcoverage criterion varies considerably between the 10,000 iterations of our last-20k experiments (Fig. 8a). While EOF1 exhibits clear similarities with the well-known succession of events that characterise the last 20,000 years, the meaning of EOF2 was less clear, and may support the results of Anchukaitis and Tierney (2013). Because our MC-RSEOF approach simultaneously integrates chronological and lake-status uncertainty, the uncertainty of its product is influenced by both factors. Since the lake-status classification system of the database is qualitative, all derived products should be treated as qualitative as well. However, quantitative information is available for a subset of the lakes of our database (Table 1) for more specific studies on climate-driven water budget.

In addition to the proposed methodology, our database format also offers major improvements in terms of uniformity and precision of lake-status chronologies over the GLSDB. The preservation of relevant information in a relational database format enables exploring and selecting sites based on sensitivity or temporal coverage, or other characteristics such as catchment size or type of chronological data. While we primarily focused on the past 20,000 years, different site selection based on density or other aspects of dating control could be advisable when studying shorter time scales or time windows. Similarly, caution is advised when studying poorly represented time windows or regions, where inclusion or exclusion of individual sites may significantly alter the resulting EOFs.

Our database format also improves upon the GLSDB in terms of uniformity and precision of lake-status chronologies. Almost one third of all reported radiocarbon dates were not calibrated upon original publication (Fig. 6). Our updated chronologies commonly resulted in significant changes in comparison to their original counterparts. An important factor in radiocarbon-based chronologies is the dated material and, correspondingly, old-carbon effects. While our data compilation conserves information on reported carbon-reservoir effects, these effects are often not investigated in the original studies, which may cast additional uncertainty even on relatively high-resolution chronologies.

Our new database approach offers a new perspective on the use of lake-status data for comparative studies between reconstructions based on natural archives and palaeoclimate model simulations. Data-model comparisons have become an integral part of evaluating model performance (Kohfeld and Harrison, 2000; Harrison et al., 2014) but their effectiveness requires standardised quantification of data uncertainty (Harrison et al., 2016). Our new database significantly improves the incorporation of such uncertainties in assessing model simulations using lakestatus data and provides significant improvements over previous lake-status syntheses, such as the widely used GLSDB.

The utility of our analytical framework combining MC sampling of uncertainties and RSEOF identification of dominant modes of variability extends beyond lake-status data. Indeed, it can be applied to any palaeoenvironmental data set that comes in the form of time series with chronological, analytical and/or interpretational uncertainties. This opens new possibilities for more inclusive syntheses, employing a standardised methodology across all archive types, data sources and palaeoenvironmental variables.

However, to enable the development of such large-scale studies, adequate reporting of data is crucial. Most of the challenges involved in assembling the ESA lake-status database were related to incomplete reporting of data. 
While we fully acknowledge that reporting data for purposes beyond the original goal of a paper can be complex and time-consuming, the following points emphasise key elements to consider in order to foster the best use of palaeolimnological data by independent groups:

- Raw data (e.g., lake-level curves, stratigraphic profiles, time series of key indicators) were not always accessible. Where the information was not available from the data producers, we had to digitise the data from figures, which at best led to a loss of data quality, and possibly to a distortion of some signals.

- Stratigraphic data series were often only expressed against the calculated age and not versus original core or section depth. The inclusion of depth information, either in the original publication or in archived data sets, is essential for future updates of the chronologies (e.g., when the radiocarbon calibration curves are updated).

- In some cases, chronological data was only presented graphically. Dating information presented in tabular form allow for both a quick assessment of the raw measurements and their errors, and contribute to a better reuse of the data (Millard, 2014; Courtney Mustaphi et al., 2019).

- The details of the construction of the published chronology were sometimes incomplete. More details on the radiocarbon calibration curve used and/or the method of interpolation between multiple age points would contribute to a more accurate reproduction of the data.

- We encourage a clear definition and discussion of which environmental variables are reconstructed based on the available evidence.

\section{Conclusion}

Lake-status histories are important sources of information on past climate change, but their synthesis and translation to palaeoclimate change is challenging. We present a new relational lake-status database that combines updated chronologies with the incorporation of uncertainties. We have shown that the combination of MC sampling to integrate the full range of data uncertainty and RSEOF to extract the dominant modes of variability allows the identification of dominant historical trends, and an assessment of their robustness. The application of this approach to ESA identified the dominant millennial-scale palaeoclimate features of the last 20,000 years, consistent with the current understanding of environmental change in the region, including a tendency towards anti-phased lake-status behaviour between the EARS and interior and eastern southern Africa. These results highlight the potential contributions lake-status data can make to large-scale palaeoclimate syntheses, despite their often discontinuous and qualitative nature. The data and methods presented here serve as a proof-of-concept study for future large-scale syntheses of lake status in other regions of the world.

\section{Data availability}

The following materials are available on the open data repository Zenodo (https://doi.org/10.5281/zenodo.4494804).

- $\quad$ The ESA lake-status database, in both SQLite and spreadsheet format.

- Description and constraints of all database fields. 
- Documentation for all sites included in the database. This includes relevant background information of the site, presentation of original literature from which lake-status information was sourced, and discussion of consensus lake-status history.

- Catchment shapefiles of all included sites.

- $\quad$ R code for MC-RSEOF analysis on our database format.

\section{Author contributions}

GDC: Project administration, Methodology, Software, Formal analysis, Investigation, Data curation, Writing original draft, Writing - review and editing, Visualisation

MC: Project administration, Methodology, Software, Investigation, Data curation, Writing - review and editing, Visualisation

SLB: Project administration, Methodology, Investigation, Writing - review and editing

CYC: Project administration, Methodology, Writing - review and editing

SPH: Supervision, Conceptualisation, Methodology, Resources, Writing - review and editing

\section{Acknowledgements}

GDC acknowledges support from the Research Foundation Flanders (FWO), the Belgian-American Educational Foundation (BAEF) and Belgian Science Policy Brain-be project BR/121/A2 PAMEXEA (Patterns and mechanisms of climate extremes in East Africa). MC has been funded by the Swiss National Science Foundation (SNF) through the HORNET project (200021_169598). SLB acknowledges support from the Trapnell Fund, Environmental Change Institute at the University of Oxford. CYC acknowledges financial support from the National Science Foundation Graduate Research Fellowship and Department of Earth, Atmospheric, and Planetary Sciences at MIT. SPH acknowledges funding from the ERC-funded project GC2.0 (Global Change 2.0: Unlocking the past for a clearer future, grant number 694481) and from JPI-Belmont Forum project entitled Palaeoclimate Constraints on Monsoon Evolution and Dynamics (PaCMEDy). We gratefully acknowledge the support of INQUA funding under the project PALCOM 1609P (Palaeolakes of the Arid Southern Hemisphere). We sincerely thank Bryan N. Shuman, David McGee, Sarah Metcalfe, Maarten Blaauw, Mengna Liao, Bronwyn Dixon, Nicholas Primmer, Luciana Figueiredo Prado and David T. Liefert for constructive discussions on synthesizing lake-status histories. 


\section{Figure captions}

Fig. 1 Examples of lake-status histories over the last 25,000 years as incorporated in the database. a) The palaeoshoreline-based reconstruction of Etosha, Namibia. b) The (mostly) sediment-core based record of Lake Naivasha, Kenya. Horizontal error bars indicate the outer limits of 2- $\sigma$ age uncertainty of each episodes' start and end as determined by reworked chronologies. Relative status class (y-axis) is qualitative, but episodes in orange are linked to quantitative information in the form of absolute water-level elevations from shorelines or other geomorphological evidence. In contrast, grey boxes depict episodes where such a link does not exist. Uncertainty in relative lake status is depicted by lighter-colored areas outlined by a dash-dotted line.c) The MC sampling process illustrated on part of Lake Naivasha's lake-status history. Start and end of subsequent lakestatus episodes are sampled from split-normal probability density functions ( $p d f$ ) defined by the $95 \%$ credible intervals provided in the database, which themselves are derived from Bayesian age-depth modelling or, in the case of palaeoshorelines, from individual geochronological data points. For each episode, status class is sampled from a triangular distribution defined by best-estimate and minimum and maximum possible status classes defined in the database.

Fig. 2 Schematic overview of the structure of the SQLite database. In addition to the 9 main tables (blue), the database contains additional tables that are either used to define lists of accepted values for specific fields (black) or to link the different data tables together (orange). The black tables help to homogenise the information that is entered in the database (e.g., basin type) and facilitate querying the data. The orange tables account for the multiple relationships that can exist between tables. For example, the LakeRefs table connects the Lakes and Refs tables because there is no one-to-one connection between the two tables: one reference can be associated with several lakes and one lake can be associated with several references. For a detailed overview of these tables, see Data availability.

Fig. 3 Flowchart of analytical approach employed in this study.

Fig. 4 Location of sites in our ESA database against a) elevation and b) aridity index, which is defined as the ratio of mean annual precipitation over mean annual evapotranspiration (MAP/MAE; Trabucco en Zomer, 2009). Map a shows whether or not the sites were incorporated in the GLSDB, while map b shows the current hydrology of the sites, with symbol colour differentiating between (seasonally) dry, closed, and open basins. Black lines delineate catchment boundaries. Site numbers refer to Table 1.

Fig. 5 a) Lake sites in the database plotted according to catchment size, best-estimate age of the earliest statusclass information, best-estimate temporal coverage, and number of defined status classes. b) Number of lakestatus episodes of each site's best-estimate history falling (partly) within 500-year bins over the last 25,000 years.

Fig. 6 a) Spatial distribution of the amount and type of chronological data points used in reworked chronologies. b) Site-specific temporal distribution of chronological data points used in reworked chronologies (coloured circles depict best-estimate age) and lake-status information (covered parts of history are denoted by a full black line). Site numbers refer to Table 1. c) Database-wide counts of chronological data points used in reworked chronologies, in 1,000-year bins according to type. 
Fig. 7 Number of sites with lake-status information through time over the last 20,000 years, for the entire database and per subregion discussed in the text, across 10,000 MC-generated historical scenarios. Full lines depict the best-estimate scenario for all sites, dark and light shading depicts the 1- $\sigma$ and 2- $\sigma$ MC uncertainty envelope.

Fig. 8 a) Overview of MC-RSEOF experiments over 20,000-0 cal yr BP on MC-generated and best-estimate lakestatus histories. Results are plotted according to the site-selection criteria that were used to retain for RSEOF analysis only those sites that met minima of temporal coverage (varying between experiments between 10 and 100 $\%)$ and lake-status episodes (2 or 4). The top row of plots shows the frequency of the number of incorporated sites across each experiment's 10,000 MC iterations. The bin also containing the number of sites in the scenario where all uncertainties are set to their best estimate, is shown by the darker shade of purple. The middle row shows the frequency of resulting non-overlapping EOFs from each experiment's 10,000 RSEOF runs, with the darker shade again depicting the value that was also obtained for the best-estimate run. The bottom row of plots shows the distribution of the variance explained by the first two EOFs across each experiment's 10,000 RSEOF runs. Values for the best-estimate scenario are depicted by a darker-shaded point. b) Time series of EOF1 from RSEOF analyses over 20,000-0 cal yr BP on MC-generated ensemble of lake-status histories. Site-selection criteria of minimum temporal coverage and defined status episodes vary between 10-100\% and 2-4, respectively. Black line depicts the median across iterations, dark grey and light grey shading depicts the 1- $\sigma$ and 2- $\sigma$ MC uncertainty envelope.

Fig. 9 Results of RSEOF analysis over 20,000-0 cal yr BP. Selection criteria for sites were a minimum of 4 defined status episodes within this time window and a temporal coverage of at least 33\%. Best-estimate histories as well as MC-sampled histories (10,000 iterations) are considered. a) Biplot of EOF1 and 2, depicting loadings of bestestimate scenario (thick-bordered circles) and means of MC-generated scenarios with 1- $\sigma$ error bars (thinbordered circles). Point size is proportional to the record's temporal coverage. Only sites for which the bestestimate history met the selection criteria are depicted. b) Lambda scores of EOFs for MC-generated (vertical columns and error bars show MC mean $\pm 1 \sigma$ ) and best-estimate (points) histories. The percentage of MC iterations in which a particular EOF is represented is shown above each column. c) EOF1 loadings of bestestimate (upper half-circles) and MC-sampled histories (lower half-circles). Half-circle size is proportional to the record's temporal coverage. Only sites for which the best-estimate history met the selection criteria are depicted. d) Time series of EOF1. The thick black line represents EOF1 of the best-estimate scenario for each site, the thin line represents the median EOF1 across MC iterations. Dark grey and light grey shading depicts the 1- $\sigma$ and 2- $\sigma$ MC uncertainty envelope. e) Same as c, but for EOF2.f) Same as d, but for EOF2. 


\section{References}

Anchukaitis, K.J., Tierney, J.E., 2013. Identifying coherent spatiotemporal modes in time-uncertain proxy paleoclimate records. Clim. Dyn. 41, 1291-1306. https://doi.org/10.1007/s00382-012-1483-0

Atsawawaranunt, K., Comas-Bru, L., Amirnezhad Mozhdehi, S., Deininger, M., Harrison, S.P., Baker, A., Boyd, M., Kaushal, N., Ahmad, S.M., Ait Brahim, Y., Arienzo, M., Bajo, P., Braun, K., Burstyn, Y., Chawchai, S., Duan, W., Hatvani, I.G., Hu, J., Kern, Z., Labuhn, I., Lachniet, M., Lechleiter, F.A., Lorrey, A., Pérez-Mejías, C., Pickering, R., Scroxton, N., 2018. The SISAL database: a global resource to document oxygen and carbon isotope records from speleothems. Earth Syst. Sci. Data Discuss. 1-64. https://doi.org/10.5194/essd-2018-17

Bartlein, P.J., Harrison, S.P., Izumi, K., 2017. Underlying causes of Eurasian midcontinental aridity in simulations of mid-Holocene climate. Geophys. Res. Lett. 44, 9020-9028. https://doi.org/10.1002/2017GL074476

Blaauw, M., 2010. Methods and code for 'classical' age-modelling of radiocarbon sequences. Quat. Geochronol. 5, 512-518. https://doi.org/10.1016/j.quageo.2010.01.002

Blaauw, M., Christen, J.A., 2011. Flexible paleoclimate age-depth models using an autoregressive gamma process. Bayesian Anal. 6, 457-474. https://doi.org/10.1214/11-BA618

Bowler, J.M., 1986. Spatial variability and hydrologic evolution of Australian lake basins: Analogue for pleistocene hydrologic change and evaporite formation. Palaeogeogr. Palaeoclimatol. Palaeoecol. 54, $21-41$. https://doi.org/10.1016/0031-0182(86)90116-1

Breitenbach, S.F.M., Rehfeld, K., Goswami, B., Baldini, J.U.L., Ridley, H.E., Kennett, D.J., Prufer, K.M., Aquino, V. V., Asmerom, Y., Polyak, V.J., Cheng, H., Kurths, J., Marwan, N., 2012. Constructing Proxy Records from Age models (COPRA). Clim. Past 8, 1765-1779. https://doi.org/10.5194/cp-8-1765-2012

Burrough, S.L., Thomas, D.S.G., 2013. Central southern Africa at the time of the African Humid Period: A new analysis of Holocene palaeoenvironmental and palaeoclimate data. Quat. Sci. Rev. 80, $29-46$. https://doi.org/10.1016/j.quascirev.2013.08.001

Burrough, S.L., Thomas, D.S.G., Bailey, R.M., 2009. Mega-Lake in the Kalahari: A Late Pleistocene record of the Palaeolake Makgadikgadi system. Quat. Sci. Rev. 28, 1392-1411. https://doi.org/10.1016/j.quascirev.2009.02.007

Burrough, S.L., Thomas, D.S.G., 2009. Geomorphological contributions to palaeolimnology on the African continent. Geomorphology 103, 285-298. https://doi.org/10.1016/j.geomorph.2008.07.015

Carlson, A.E., 2013. The Younger Dryas climate event, in: The Encyclopedia of Quaternary Science, Vol. 3. Elsevier, Amsterdam, pp. 126-134.

Chase, B.M., Meadows, M.E., Carr, A.S., Reimer, P.J., 2010. Evidence for progressive Holocene aridification in southern Africa recorded in Namibian hyrax middens: Implications for African Monsoon dynamics and the ““African Humid Period.” Quat. Res. 74, 36-45. https://doi.org/10.1016/j.yqres.2010.04.006

Chase, B.M., Niedermeyer, E.M., Boom, A., Carr, A.S., Chevalier, M., He, F., Meadows, M.E., Ogle, N., Reimer, P.J., 2019. Orbital controls on Namib Desert hydroclimate over the past 50,000 years. Geology 47, 867-871. https://doi.org/10.1130/G46334.1

Cheddadi, R., Yu, G., Guiot, J., Harrison, S.P., Prentice, I.C., 1996. The climate of Europe 6000 years ago. Clim. Dyn. 13, 1-9. https://doi.org/10.1007/s003820050148

Chen, C.Y., Maloof, A.C., 2017. Revisiting the deformed high shoreline of Lake Bonneville. Quat. Sci. Rev. 159, 169-189. https://doi.org/10.1016/j.quascirev.2016.12.019

Chen, C.Y., McGee, D., Woods, A., Pérez, L., Hatfield, R.G., Edwards, R.L., Cheng, H., Valero-Garcés, B. L., Lehmann, S.B., Stoner, J.S., Schwalb, A., Tal, I., Seltzer, G.O., Tapia, P.M., Abbott, M.A., Rodbell, D.T., 
2020. U-Th dating of lake sediments: Lessons from the 700 ka sediment record of Lake Junín, Peru. Quaternary Science Reviews. 244: 106422. https://doi.org/10.1016/j.quascirev.2020.106422

Chevalier, M., Chase, B.M., 2015. Southeast African records reveal a coherent shift from high- to low-latitude forcing mechanisms along the east African margin across last glacial-interglacial transition. Quat. Sci. Rev. 125, 117-130. https://doi.org/10.1016/j.quascirev.2015.07.009

Chorowicz, J., 2005. The East African rift system. J. African Earth Sci. 43, 379-410. https://doi.org/10.1016/j.jafrearsci.2005.07.019

Coe, T., Harrison, P., 2002. The water balance of northern Africa during the mid-Holocene : an evaluation of the 6 ka BP PMIP simulations 155-166. https://doi.org/10.1007/s00382-001-0219-3

Comas-Bru, L., Harrison, S.P., Werner, M., Rehfeld, K., Scroxton, N., Veiga-Pires, C., 2019. Evaluating model outputs using integrated global speleothem records of climate change since the last glacial. Clim. Past 15, 1557-1579. https://doi.org/10.5194/cp-15-1557-2019

Courtney Mustaphi, C.J., Brahney, J., Aquino-López, M.A., Goring, S., Orton, K., Noronha, A., Czaplewski, J., Asena, Q., Paton, S., Panga Brushworth, J., 2019. Guidelines for reporting and archiving 210Pb sediment chronologies to improve fidelity and extend data lifecycle. Quat. Geochronol. 52, 77-87. https://doi.org/10.1016/j.quageo.2019.04.003

De Cort, G., Verschuren, D., Ryken, E., Wolff, C., Renaut, R.W., Creutz, M., Van der Meeren, T., Haug, G., Olago, D.O., Mees, F., 2018. Multi-basin depositional framework for moisture-balance reconstruction during the last 1300 years at Lake Bogoria, central Kenya Rift Valley. Sedimentology 38, 1667-1696. https://doi.org/10.1111/sed.12442

Delalande, M., 2008. Hydrologie et geochimie isotopique du Lac Masoko et des lacs volcaniques de la province active du Rungwe (Sud-Ouest Tanzanie). Université Paris Sud.

deMenocal, P., Ortiz, J., Guilderson, T., Adkins, J., Sarnthein, M., Baker, L., Yarusinsky, M., 2000. Abrupt onset and termination of the African Humid Period: Quat. Sci. Rev. 19, 347-361. https://doi.org/10.1016/S02773791(99)00081-5

Digerfeldt, G., 1965. Vielången och Farlången. En utvecklingshistorisk insjöundersrkning. Skånes Natur 52, 162183.

Eggermont, H., Russell, J.M., Schettler, G., Van Damme, K., Bessems, I., Verschuren, D., 2007. Physical and chemical limnology of alpine lakes and pools in the Rwenzori Mountains (Uganda-DR Congo). Hydrobiologia 592, 151-173. https://doi.org/10.1007/s10750-007-0741-3

Eggermont, H., Verschuren, D., 2007. Taxonomy and diversity of Afroalpine Chironomidae (Insecta: Diptera) on Mount Kenya and the Rwenzori Mountains, East Africa. J. Biogeogr. 34, 69-89. https://doi.org/10.1111/j.1365-2699.2006.01590.x

Fang, J., 1991. Lake evolution during the past 30,000 years in China, and its implications for environmental change. Quat. Res. 36, 37-60. https://doi.org/10.1016/0033-5894(91)90016-X

Garcin, Y., Junginger, A., Melnick, D., Olago, D.O., Strecker, M.R., Trauth, M.H., 2009. Late PleistoceneHolocene rise and collapse of Lake Suguta, northern Kenya Rift. Quat. Sci. Rev. 28, 911-925. https://doi.org/10.1016/j.quascirev.2008.12.006

Gasse, F., 2000. Hydrological changes in the African tropics since the Last Glacial Maximum. Quat. Sci. Rev. 19, 189-211. https://doi.org/10.1016/S0277-3791(99)00061-X

Gasse, F., Chalié, F., Vincens, A., Williams, M.A.J., Williamson, D., 2008. Climatic patterns in equatorial and southern Africa from 30,000 to 10,000 years ago reconstructed from terrestrial and near-shore proxy data. Quat. Sci. Rev. 27, 2316-2340. https://doi.org/10.1016/j.quascirev.2008.08.027 
Goudie, A., Thomas, D.S.G., 1986. Lunette dunes in southern Africa. J. Arid Environ. 10, 1-12. https://doi.org/10.1016/S0140-1963(18)31260-6

Haddon, I.G., McCarthy, T.S., 2005. The Mesozoic-Cenozoic interior sag basins of Central Africa: The LateCretaceous-Cenozoic Kalahari and Okavango basins. J. African Earth Sci. 43, 316-333. https://doi.org/10.1016/j.jafrearsci.2005.07.008

Harrison, S.P., 1989. Lake levels and climatic change in eastern North America. Clim. Dyn. 3, 157-167. https://doi.org/10.1007/BF01080366

Harrison, S.P., 1993. Late Quaternary lake-level changes and climates of Australia. Quat. Sci. Rev. 12, $211-231$. https://doi.org/10.1016/0277-3791(93)90078-Z

Harrison, S.P., Saarse, L., Digerfeldt, G., 1991. Holocene changes in lake levels as climate proxy data in Europe. Paleoklimaforschung 6, 159-170.

Harrison, S.P., Digerfeldt, G., 1993. European lakes as palaeohydrological and palaeoclimatic indicators. Quat. Sci. Rev. 12, 233-248. https://doi.org/10.1016/0277-3791(93)90079-2

Harrison, S.P., Prentice, I.C., Guiot, J., 1993. Climatic controls on Holocene lake-level changes in Europe. Clim. Dyn. 8, 189-200. https://doi.org/10.1007/BF00207965

Harrison, S.P., Yu, G., Tarasov, P.E., 1996. Late Quaternary Lake-Level Record from Northern Eurasia. Quat. Res. 45, 138-159. https://doi.org/10.1006/qres.1996.0016

Harrison, S.P., Yu, G., Vassiljev, J., 2002. Climate changes during the Holocene recorded by lakes from Europe, in: Climate Development and History of the North Atlantic Realm. Springer, Berlin, Heidelberg, pp. 191-204.

Harrison, S.P., Bartlein, P.J., Brewer, S., Prentice, I.C., Boyd, M., Hessler, I., Holmgren, K., Izumi, K., Willis, K., 2014. Climate model benchmarking with glacial and mid-Holocene climates. Clim. Dyn. 43, 671-688. https://doi.org/10.1007/s00382-013-1922-6

Harrison, S.P., Bartlein, P.J., Prentice, I.C., 2016. What have we learnt from palaeoclimate simulations? J. Quat. Sci. 31, 363-385. https://doi.org/10.1002/jqs.2842

Hatfield, R., Stoner, J., Solada, K.E., Morey, A.E., Woods, A., Chen, C.Y., McGee, D., Abbott, M.B., Rodbell, D.T., 2020. Paleomagnetic Constraint of the Brunhes Age Sedimentary Record from Lake Junín, Peru. Frontiers in Earth Science 8. https://doi.org/10.3389/feart.2020.00147.

Heegaard, E., Birks, H.J.B., Telford, R.J., 2005. Relationships between calibrated ages and depth in stratigraphical sequences: an estimation procedure by mixed-effect regression. The Holocene 15, 612-618. https://doi.org/10.1191/0959683605hl836rr

Hill, B.J., 1975. The origin of southern African coastal lakes. Trans. R. Soc. South Africa 41, $225-240$. https://doi.org/10.1080/00359197509519440

Hogg, A.G., Hua, Q., Blackwell, P.G., Niu, M., Buck, C.E., Guilderson, T.P., Heaton, T.J., Palmer, J.G., Reimer, P.J., Reimer, R.W., Turney, C.S.M., Zimmerman, S.R.H., 2013. SHCal13 Southern Hemisphere Calibration, 0-50,000 Years cal BP. Radiocarbon 55, 1889-1903. https://doi.org/10.2458/azu_js_rc.55.16783

Holmes, J., Hoelzmann, P., 2017. The Late Pleistocene-Holocene African Humid Period as Evident in Lakes. Oxford University Press. https://doi.org/10.1093/acrefore/9780190228620.013.531

Jolly, D., Prentice, I.C., Bonnefille, R., Ballouche, A., Bengo, M., Brenac, P., Buchet, G., Burney, D., Cazet, J., Cheddadi, R., Edorh, T., Elenga, H., Elmoutaki, S., Guiot, J., Laarif, F., Lamb, H., Lezine, A., Maley, J., Mbenza, M., Peyron, O., Reille, M., Reynaud-Farrera, I., Riollet, G., Ritchie, J.C., Roche, E., Scott, L., Ssemmanda, I., Straka, H., Umer, M., Van Campo, E., Vilimumbalo, S., Vincens, A., Waller, M., 1998. Biome reconstruction from pollen and plant macrofossil data for Africa and the Arabian peninsula at 0 and 6000 years. J. Biogeogr. 25, 1007-1027. https://doi.org/10.1046/j.1365-2699.1998.00238.x 
Juggins, S., 2013. Quantitative reconstructions in palaeolimnology: new paradigm or sick science? Quat. Sci. Rev. 64, 20-32. https://doi.org/10.1016/j.quascirev.2012.12.014

Kalff, J., 2001. Chapter 5: Hydrology and climate, in: Limnology. Prentice Hall, Upper Saddle River, New Jersey, pp. 53-71.

Kohfeld, K.E., Harrison, S.P., 2000. How well can we simulate past climates? Evaluating the models using global palaeoenvironmental datasets 19 .

Kutterolf, S., Schindlbeck, J.C., Anselmetti, F.S., Ariztegui, D., Brenner, M., Curtis, J., Schmid, D., Hodell, D., Mueller, A., Pérez, W., Schwalb, A., Frische, M., Wang, K.L., 2016. A 400-ka tephrochronological framework for Central America from Lake Petén Itzá (Guatemala) sediments. Quaternary Science Reviews 150, 200-220. https://doi.org/10.1016/j.quascirev.2016.08.023.

Kutzbach, J.E., Otto-Bliesner, B.L., 1982. The Sensitivity of the African-Asian Monsoonal Climate to Orbital Parameter Changes for 9000 Years B.P. in a Low-Resolution General Circulation Model. J. Atmos. Sci. 39, 1177-1188. https://doi.org/10.1175/1520-0469(1982)039<1177:TSOTAA>2.0.CO;2

Legendre, P., Legendre, L.F.J., 2012. Numerical Ecology Volume 24 Developments in Environmental Modelling. Elsevier.

Lehner, B., Verdin, K., Jarvis, A., 2008. New Global Hydrography Derived From Spaceborne Elevation Data. Eos, Trans. Am. Geophys. Union 89, 93. https://doi.org/10.1029/2008EO100001

Liu, G., Schwartz, F.W., 2014. On modeling the paleohydrologic response of closed-basin lakes to fluctuations in climate: Methods, applications, and implications. Water Resour. Res. 50, 2975-2992. https://doi.org/10.1002/2013WR014107

Liu, X., Rendle-Bühring, R., Kuhlmann, H., Li, A., 2017. Two phases of the Holocene East African Humid Period: Inferred from a high-resolution geochemical record off Tanzania. Earth Planet. Sci. Lett. 460, 123-134. https://doi.org/10.1016/j.epsl.2016.12.016

Lohmann, G., Pfeiffer, M., Laepple, T., Leduc, G., Kim, J.-H., 2013. A model-data comparison of the Holocene global sea surface temperature evolution. Clim. Past 9, 1807-1839. https://doi.org/10.5194/cp-9-1807-2013

Mahaney, W.C., 2004. Quaternary Glacial Chronology of Mount Kenya Massif, in: Ehlers, J., Gibbard, P. (Eds.), Quaternary Glaciations - Extent and Chronology, Part III. Elsevier B.V., pp. 227-231.

Mason, I.M., Guzkowska, M.A.J., Rapley, C.G., Street-Perrott, F.A., 1994. The response of lake levels and areas to climatic change. Clim. Change 27, 161-197. https://doi.org/10.1007/BF01093590

McKay, N.P., Kaufman, D.S., 2014. An extended Arctic proxy temperature database for the past 2,000 years. Sci. Data 1, 140026. https://doi.org/10.1038/sdata.2014.26

Melack, J.M., 1978. Morphometric, physical and chemical features of the volcanic crater lakes of western Uganda. Arch. fur Hydrobiol. 84, 430-453.

Meybeck, M., 1995. Global distribution of lakes, in: Lerman, A., Imboden, D.M., Gat, J.R. (Eds.), Physics and Chemistry of Lakes. Springer-Verlag Berlin Heidelberg, pp. 1-36.

Millard, A.R., 2014. Conventions for Reporting Radiocarbon Determinations. Radiocarbon 56, 555-559. https://doi.org/10.2458/56.17455

Nicholson, S.E., 2018. The ITCZ and the seasonal cycle over equatorial Africa. Bull. Am. Meteorol. Soc. 99, 337-348. https://doi.org/10.1175/BAMS-D-16-0287.1

Nicholson, S.E., 2017. Climate and climatic variability of rainfall over eastern Africa. Rev. Geophys. 55, 590635. https://doi.org/10.1002/2016RG000544 
North, G.R., Bell, T.L., Cahalan, R.F., Moeng, F.J., 1982. Sampling Errors in the Estimation of Empirical Orthogonal Functions. Mon. Weather Rev. 110, 699-706. https://doi.org/10.1175/15200493(1982)110<0699:SEITEO>2.0.CO;2

Olaka, L.A., Odada, E.O., Trauth, M.H., Olago, D.O., 2010. The sensitivity of East African rift lakes to climate fluctuations. J. Paleolimnol. 44, 629-644. https://doi.org/10.1007/s10933-010-9442-4

Otto-Bliesner, B.L., Russell, J.M., Clark, P.U., Liu, Z., Overpeck, J.T., Konecky, B., DeMenocal, P., Nicholson, S.E., He, F., Lu, Z., 2014. Coherent changes of southeastern equatorial and northern African rainfall during the last deglaciation. Science (80-. ). 346, 1223-1227. https://doi.org/10.1126/science.1259531

Parnell, A.C., Buck, C.E., Doan, T.K., 2011. A review of statistical chronology models for high-resolution, proxybased Holocene palaeoenvironmental reconstruction. Quat. Sci. Rev. 30, 2948-2960. https://doi.org/10.1016/j.quascirev.2011.07.024

Qin, B., Harrison, S.P., Kutzbach, J.E., 1998. Evaluation of modelled regional water balance using lake status data. Quat. Sci. Rev. 17, 535-548. https://doi.org/10.1016/S0277-3791(98)00011-0

R Core Team 2020. R: A language and environment for statistical computing. R Foundation for Statistical Computing, Vienna, Austria. URL https://www.R-project.org/

Rasmussen, S.O., Andersen, K.K., Svensson, A.M., Steffensen, J.P., Vinther, B.M., Clausen, H.B., SiggaardAndersen, M.-L., Johnsen, S.J., Larsen, L.B., Dahl-Jensen, D., Bigler, M., Röthlisberger, R., Fischer, H., GotoAzuma, K., Hansson, M.E., Ruth, U., 2006. A new Greenland ice core chronology for the last glacial termination. J. Geophys. Res. 111, D06102. https://doi.org/10.1029/2005JD006079

Reid, R.E.B., Jones, M., Brandt, S., Bunn, H., Marshall, F., 2019. Oxygen isotope analyses of ungulate tooth enamel confirm low seasonality of rainfall contributed to the African Humid Period in Somalia. Palaeogeogr. Palaeoclimatol. Palaeoecol. 534, 109272. https://doi.org/10.1016/j.palaeo.2019.109272

Reimer, P.J., Bard, E., Bayliss, A., Beck, J.W., Blackwell, P.G., Ramsey, C.B., Buck, C.E., Cheng, H., Edwards, R.L., Friedrich, M., Grootes, P.M., Guilderson, T.P., Haflidason, H., Hajdas, I., Hatté, C., Heaton, T.J., Hoffmann, D.L., Hogg, A.G., Hughen, K.A., Kaiser, K.F., Kromer, B., Manning, S.W., Niu, M., Reimer, R.W., Richards, D.A., Scott, E.M., Southon, J.R., Staff, R.A., Turney, C.S.M., van der Plicht, J., 2013. IntCal13 and Marine13 Radiocarbon Age Calibration Curves 0-50,000 Years cal BP. Radiocarbon 55, 18691887. https://doi.org/10.2458/azu_js_rc.55.16947

Roberts, H.M., Bryant, C.L., Huws, D.G., Lamb, H.F., 2018. Generating long chronologies for lacustrine sediments using luminescence dating: a 250,000 year record from Lake Tana, Ethiopia. Quat. Sci. Rev. 202, 66-77. https://doi.org/10.1016/j.quascirev.2018.10.037.

Schagerl, M., Renaut, R.W., 2016. Dipping into the soda lakes of East Africa, in: Schagerl, M. (Ed.), Soda Lakes of East Africa. Springer International Publishing Switzerland, pp. 3-24.

Schneider, R., Tobolski, K., 1985. Lago di Ganna - Late glacial and Holocene environments of a lake in the southern Alps. Diss. Bot. 87, 229-271.

Shanahan, T.M., McKay, N.P., Hughen, K.A., Overpeck, J.T., Otto-Bliesner, B., Heil, C.W., King, J., Scholz, C., Peck, J., 2015. The time-transgressive termination of the African Humid Period. Nat. Geosci. 8, 144-144. https://doi.org/10.1038/ngeo2329

Shuman, B., Henderson, A.K., Colman, S.M., Stone, J.R., Fritz, S.C., Stevens, L.R., Power, M.J., Whitlock, C. 2009. Holocene lake-level trends in the Rocky Mountains, U.S.A. Quaternary Science Reviews. 28(19-20), 1861-1879. https://doi.org/10.1016/j.quascirev.2009.03.003

Singarayer, J.S., Burrough, S.L., 2015. Interhemispheric dynamics of the African rainbelt during the late Quaternary. Quat. Sci. Rev. 124, 48-67. https://doi.org/10.1016/j.quascirev.2015.06.021 
Singarayer, J.S., Williams, C., Koriche, S., Dadson, S., Burrough, S.L., 2019. Modelling late Quaternary surface hydrology changes and climate feedbacks over African drylands, in: 20th Congress of the International Union for Quaternary Research (INQUA). Dublin, Ireland.

Specht, T., Rosendahl, B., 1989. Architecture of the Lake Malawi Rift, East Africa. J. African Earth Sci. 8, 355382.

Stager, J.C., Ryves, D.B., Chase, B.M., Pausata, F.S.R., 2011. Catastrophic Drought in the Afro-Asian Monsoon Region During Heinrich Event 1. Science (80-. ). 331, 1299-1302. https://doi.org/10.1126/science.1198322

Stager, J.C., Mayewski, P.A., Meeker, L.D., 2002. Cooling cycles, Heinrich event 1, and the desiccation of Lake Victoria. Palaeogeogr. Palaeoclimatol. Palaeoecol. 183, 169-178. https://doi.org/10.1016/S00310182(01)00468-0

Steiger, N.J., Smerdon, J.E., Cook, E.R., Cook, B.I., 2018. A reconstruction of global hydroclimate and dynamical variables over the Common Era. Sci. Data 5:180086. https://doi.org/10.1038/sdata.2018.86

Stone, A.E.C., 2014. Last Glacial Maximum conditions in southern Africa. Prog. Phys. Geogr. Earth Environ. 38, 519-542. https://doi.org/10.1177/0309133314528943

Street, F.A., Grove, A.T., 1979. Global Maps of Lake-Level Fluctuations since 30,000 yr B.P. Quat. Res. 12, 83118. https://doi.org/10.1016/0033-5894(79)90092-9

Street, F.A., 1980. The relative importance of climate and local hydrogeological factors in influencing lake-level fluctuations. Palaeoecol. Africa 12, 137-158.

Tarasov, P.E., Harrison, S.P., Saarse, L., Pushenko, M.Y., Andreev, A.A., Aleshinskaya, Z. V., Davydova, N.N., Dorofeyuk, N.I., Efremov, Y. V., Khomutova, V.I., Sevastyanov, D. V., Tamosaitis, J., Uspenskaya, O.N., Yakushko, O.F., Tarasova, I. V., 1994. Lake status records from the Former Soviet Union and Mongolia, data base documentation. NOAA Paleoclimatology Publications Series Report 2. Boulder.

Taylor, M., 2017. sinkr: Collection of functions with emphasis on multivariate data analysis. R package version 0.6 .

Taylor, M.H., Losch, M., Wenzel, M., Schröter, J., 2013. On the sensitivity of field reconstruction and prediction using empirical orthogonal functions derived from Gappy data. J. Clim. 26, 9194-9205. https://doi.org/10.1175/JCLI-D-13-00089.1

Telfer, M.W., Thomas, D.S.G., 2006. Complex Holocene lunette dune development, South Africa: Implications for paleoclimate and models of pan development in arid regions. Geology 34, 853. https://doi.org/10.1130/G22791.1

Telford, R.J., Heegaard, E., Birks, H.J.B., 2004. Alle age-depth models are wrong: but how badly? Quat. Sci. Rev. 23, 1-5. https://doi.org/10.1016/j.quascirev.2003.11.003

Thomas, D., 2016. Desert dune environments, in: Knight, J., Grab, S.W. (Eds.), Environmental Change in Southern Africa: Physical and Human Dimensions. Cambridge University Press, Cambridge.

Tiercelin, J.-J., Gibert, E., Umer, M., Bonnefille, R., Disnar, J.-R., Lézine, A.-M., Hureau-Mazaudier, D., Travi, Y., Keravis, D., Lamb, H.F., 2008. High-resolution sedimentary record of the last deglaciation from a highaltitude lake in Ethiopia. Quat. Sci. Rev. 27, 449-467. https://doi.org/10.1016/j.quascirev.2007.11.002

Tiercelin, J.-J., Lezzar, K.E., 2002. A 300 million years history of rift lakes in Central and East Africa: an updated broad review, in: Odada, E., Olago, D.O. (Eds.), The East African Great Lakes: Limnology, Palaeolimnology and Biodiversity. Kluwer Academic Publishers, pp. 3-60.

Tierney, J.E., Lewis, S.C., Cook, B.I., LeGrande, A.N., Schmidt, G.A., 2011. Model, proxy and isotopic perspectives on the East African Humid Period. Earth Planet. Sci. Lett. 307, 103-112. https://doi.org/10.1016/j.epsl.2011.04.038 
Tierney, J.E., Smerdon, J.E., Anchukaitis, K.J., Seager, R., 2013. Multidecadal variability in East African hydroclimate controlled by the Indian Ocean. Nature 493, 389-392. https://doi.org/10.1038/nature11785

Trabucco, A., Zomer, R., 2009. Global aridity index (Global-Aridity) and global potential evapotranspiration (Global-PET) geospatial database [WWW Document]. CGIAR Consort. Spat. Inf. URL http://www.csi.cgiar.org

Tyson, P.D., Preston-Whyte, R., 2000. The weather and climate of southern Africa. Oxford University Press, Cape Town.

Vassiljev, J., Harrison, S.P., Guiot, J., 1998. Simulating the Holocene Lake-Level Record of Lake Bysjön, Southern Sweden. Quat. Res. 49, 62-71. https://doi.org/10.1006/qres.1997.1942

Verschuren, D., 2003. Lake-based climate reconstruction in Africa: progress and challenges. Hydrobiologia 500, 315-330. https://doi.org/10.1023/A:1024686229778

Wang, L., Brook, G.A., Burney, D.A., Voarintsoa, N.R.G., Liang, F., Cheng, H., Edwards, R.L., 2019. The African Humid Period, rapid climate change events, the timing of human colonization, and megafaunal extinctions in Madagascar during the Holocene: Evidence from a $2 \mathrm{~m}$ Anjohibe Cave stalagmite. Quat. Sci. Rev. 210, 136-153. https://doi.org/10.1016/j.quascirev.2019.02.004

Weldeab, S., Lea, D.W., Schneider, R.R., Andersen, N., 2007. 155,000 years of West African Monsoon and ocean thermal evolution. Science 316, 1303-1307. https://doi.org/10.1126/science.1140461

Winkler, M.G., Swain, A.M., Kutzbach, J.E., 1986. Middle Holocene Dry Period in the Northern Midwestern United States: Lake Levels and Pollen Stratigraphy. Quat. Res. 25, 235-250. https://doi.org/10.1016/00335894(86)90060-8

Whitfield, A.K., Weerts, S.P., Weyl, O.L.F., 2017. A review of the influence of biogeography, riverine linkages, and marine connectivity on fish assemblages in evolving lagoons and lakes of coastal southern Africa. Ecol. Evol. 7, 7382-7398. https://doi.org/10.1002/ece3.3266

Yi, G., Zhang, T., 2015. Delayed Response of Lake Area Change to Climate Change in Siling Co Lake, Tibetan Plateau, from 2003 to 2013. Int. J. Environ. Res. Public Health 12, 13886-13900. https://doi.org/10.3390/ijerph121113886

Yu, G., Harrison, S.P., 1996. An evaluation of the simulated water balance of Eurasia and northern Africa at 6000 y BP using lake status data. Clim. Dyn. 12, 723-735. https://doi.org/10.1007/s003820050139 
Fig. 1

A Etosha, Namibia

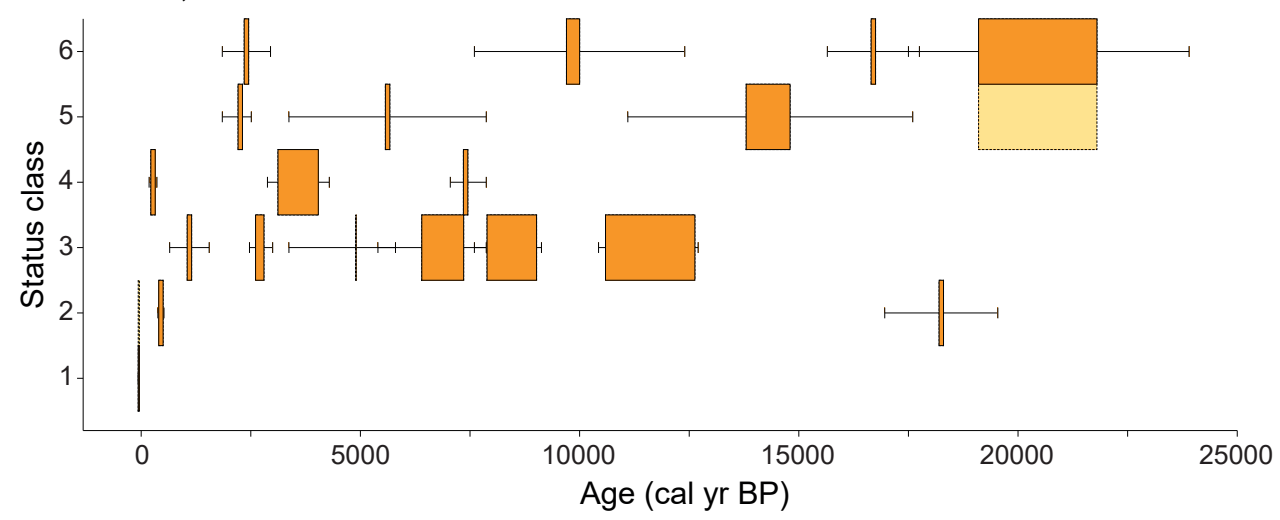

B Lake Naivasha, Kenya

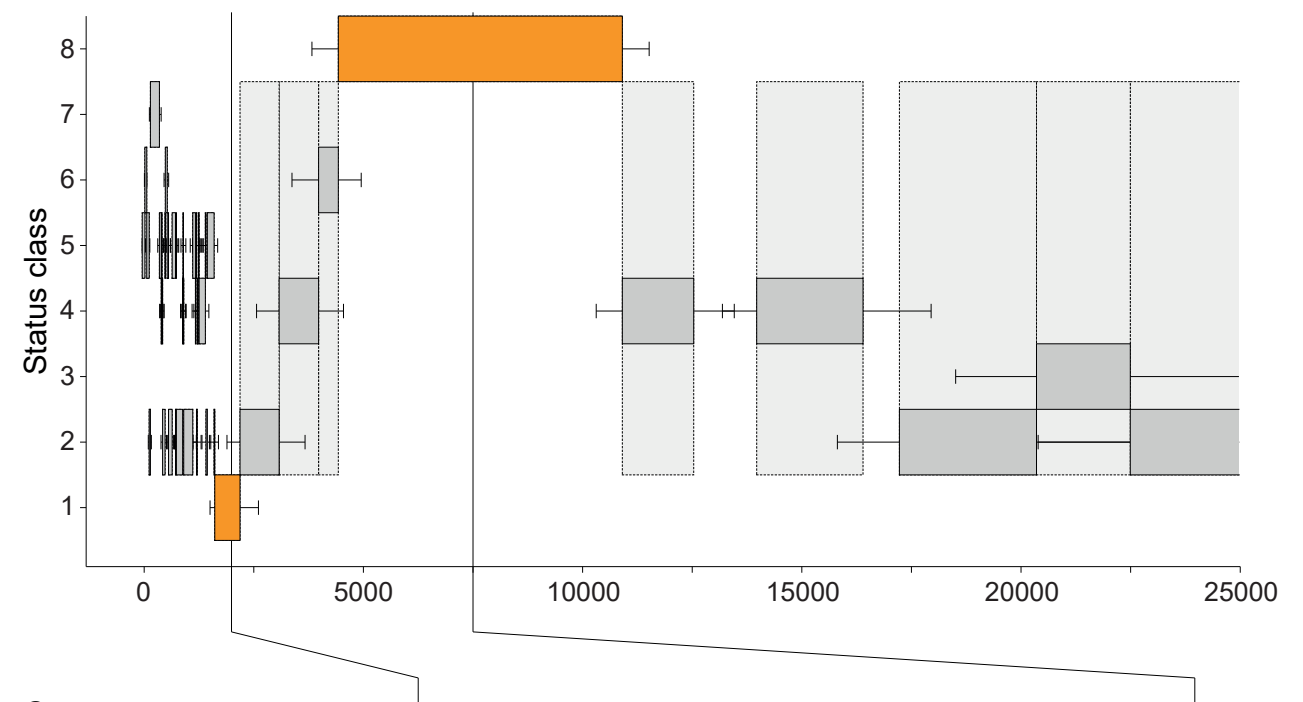

C

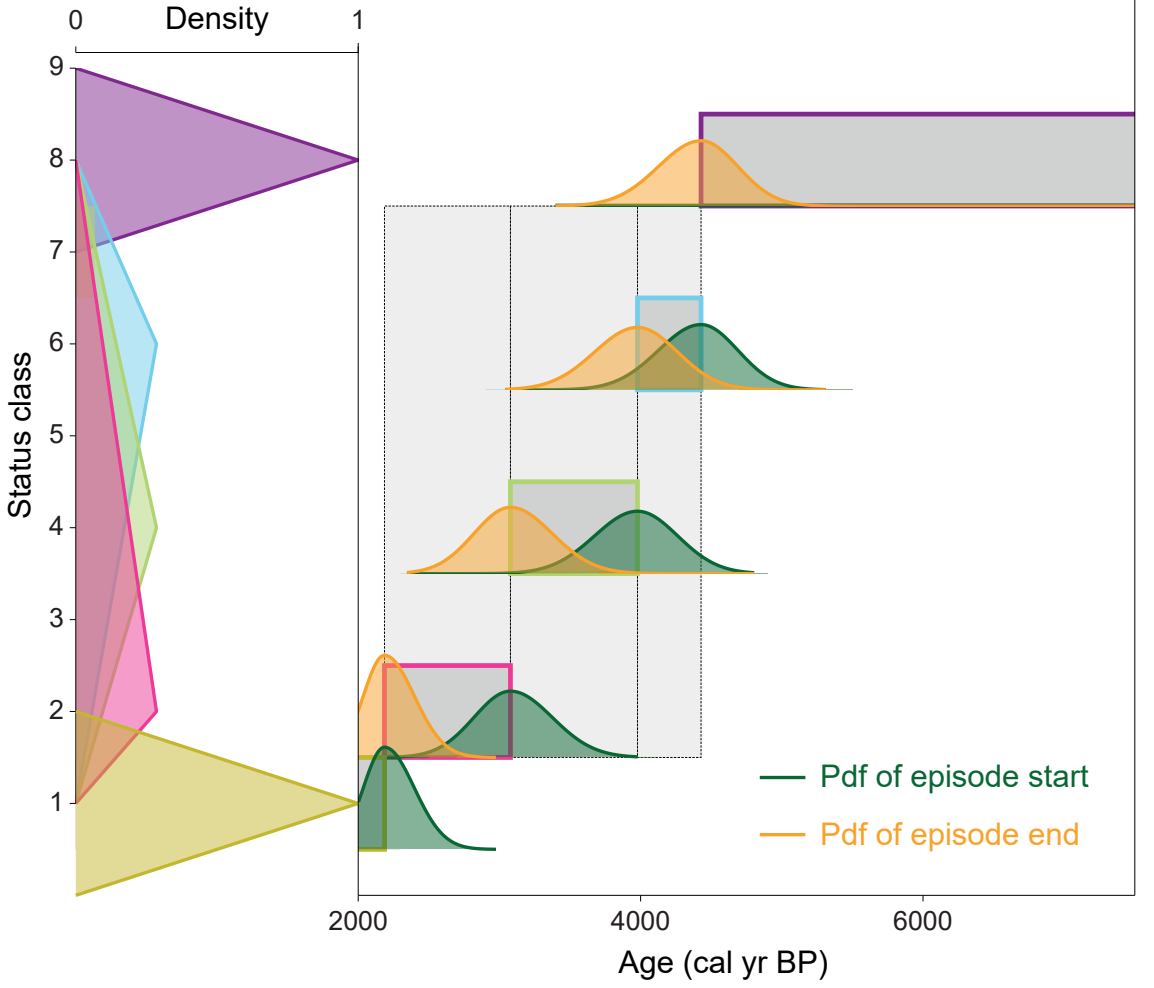


Fig. 2

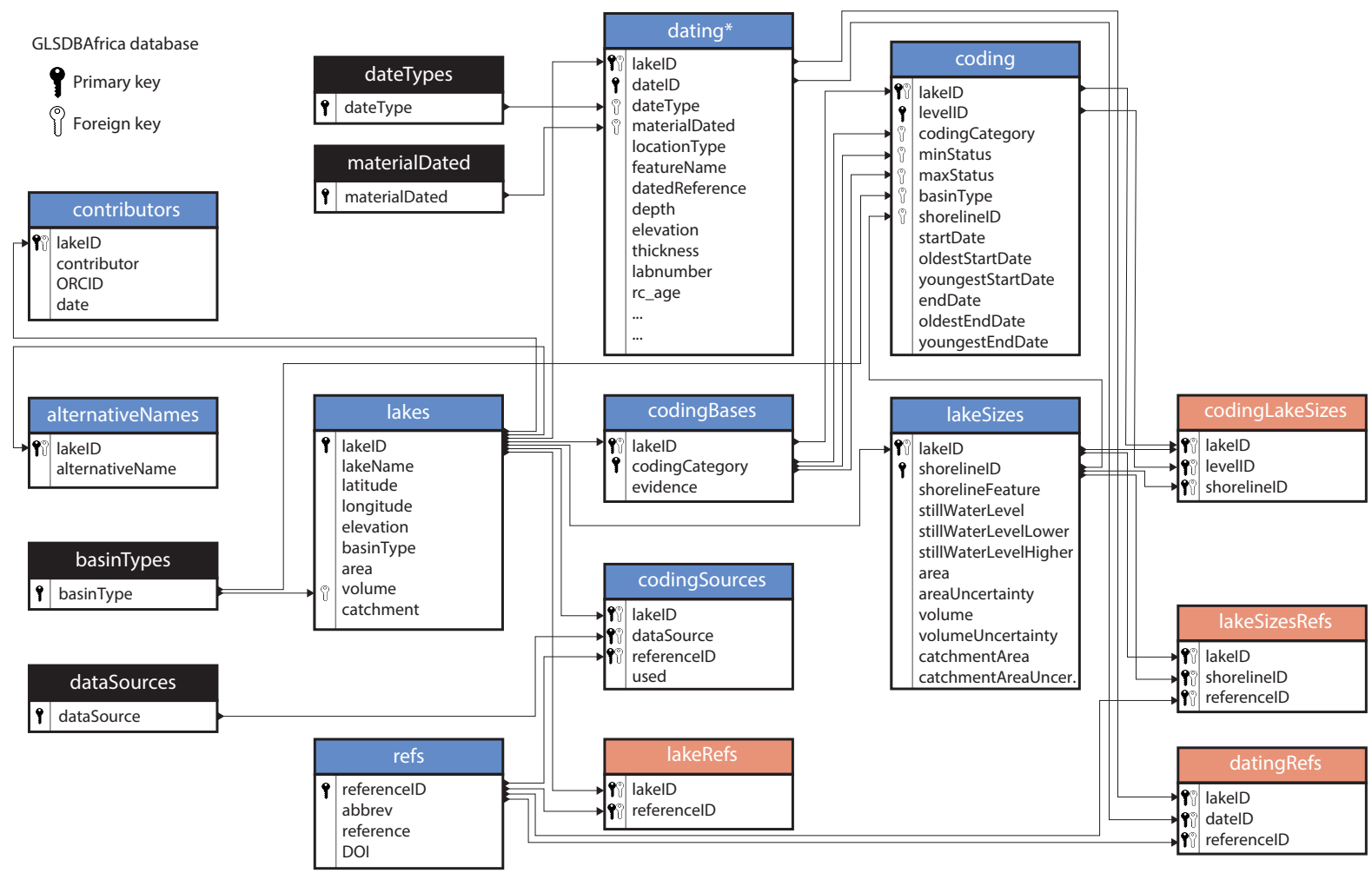


Fig. 3

I

\begin{tabular}{|lllll}
\hline $\begin{array}{c}\text { Probabilistic lake-status } \\
\text { histories with defined }\end{array}$ & Lake 1 & Lake 2 & ... & Lake $x$
\end{tabular}

$\downarrow \downarrow \downarrow \begin{gathered}\text { MC sampling } \\ \text { generates scenarios of possible } \\ \text { (i.e., allowed by the uncertainties) } \\ \text { time series of lake status. }\end{gathered} \downarrow$

\begin{tabular}{|c|c|c|c|c|c|}
\hline \multirow{2}{*}{$\begin{array}{l}\text { MC scenario } 1 \\
\text { MC scenario } 2\end{array}$} & Lake 1 & Lake 2 & $\cdots$ & Lake x & $\longrightarrow$ \\
\hline & Lake 1 & Lake 2 & $\cdots$ & Lake $x$ & $\longrightarrow$ \\
\hline MC scenario 3 & Lake 1 & Lake 2 & $\cdots$ & Lake x & $\longrightarrow$ \\
\hline$\vdots$ & $\vdots$ & $\vdots$ & & $\vdots$ & \\
\hline MC scenario 10,000 & Lake 1 & Lake 2 & $\cdots$ & Lake $x$ & $\longrightarrow$ \\
\hline \multicolumn{5}{|c|}{$\begin{array}{l}\text { In addition to the MC-generated scenarios, a scenario is created where all uncertainties are } \\
\text { set to their best estimate. }\end{array}$} & $\begin{array}{c}\text { RSEOF } \\
\text { identifies dominant } \\
\text { patterns of variability } \\
\text { in each scenario. }\end{array}$ \\
\hline best-estimate scenario & Lake 1 & Lake 2 & $\ldots$ & Lake $x$ & $\longrightarrow$ \\
\hline
\end{tabular}

III

$\begin{array}{cccc}\text { EOF PC 1 } & \text { EOF PC 2 } & \ldots & \text { EOF PC x-1 } \\ \text { EOF PC 1 } & \text { EOF PC 2 } & \ldots & \text { EOF PC x-1 } \\ \text { EOF PC 1 } & \text { EOF PC 2 } & \ldots & \text { EOF PC x-1 } \\ \vdots & \vdots & & \vdots \\ \text { EOF PC 1 } & \text { EOF PC 2 } & \ldots & \text { EOF PC x-1 } \\ \downarrow & \downarrow & & \downarrow \\ \begin{array}{c}\text { EOF PC 1 } \\ \text { ensemble }\end{array} & \begin{array}{c}\text { EOF PC 2 } \\ \text { ensemble }\end{array} & \ldots & \begin{array}{c}\text { EOF PC x-1 } \\ \text { ensemble }\end{array} \\ & & & \\ \text { EOF PC 1 } & \text { EOF PC 2 } & \ldots & \text { EOF PC } x-1\end{array}$


a

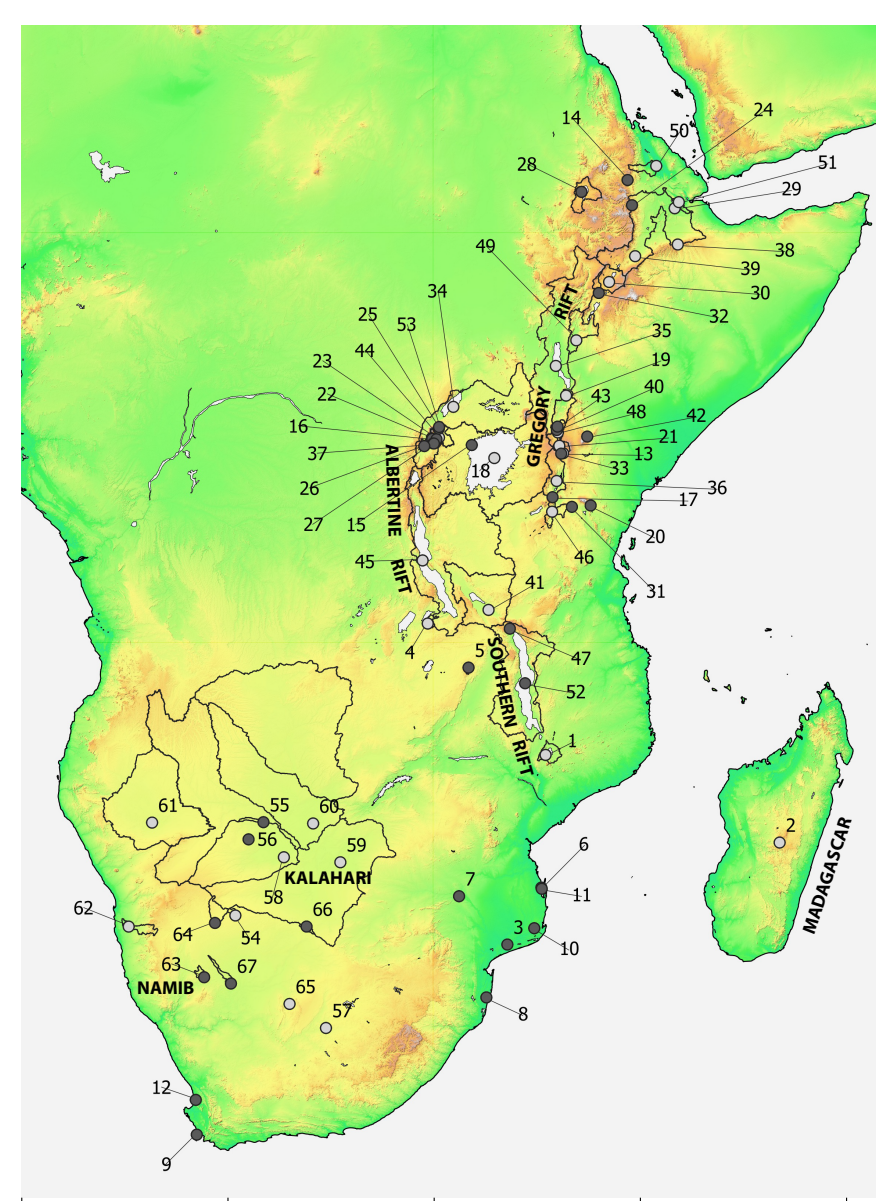

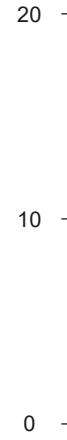

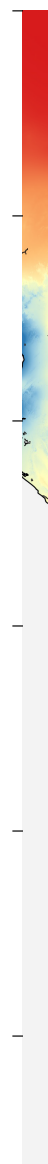

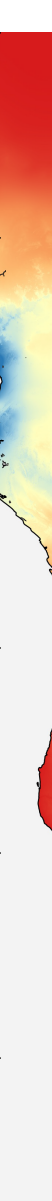
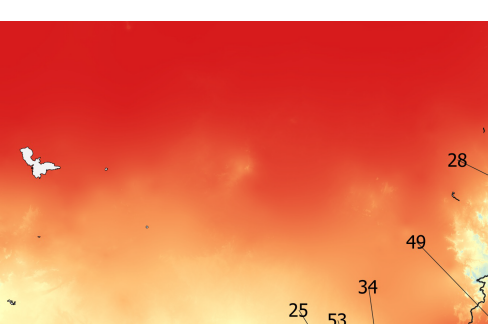

h

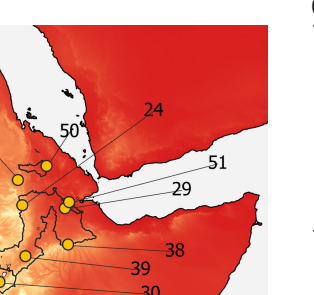

Number of lakes

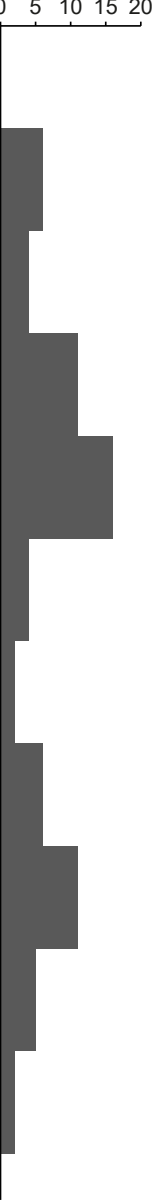

In GLSDB

$\circ$ yes
$\circ$ no
Lake type

- (seasonally)

○ closed

Elevation (
\begin{tabular}{|l}
\hline 4000 \\
-3000 \\
-2000 \\
-1000 \\
0
\end{tabular}

MAP/MAE
\begin{tabular}{|l}
\hline 2 \\
-1.5 \\
1 \\
0.5 \\
0
\end{tabular}

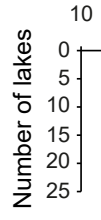

20

30

40

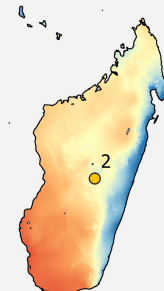

50

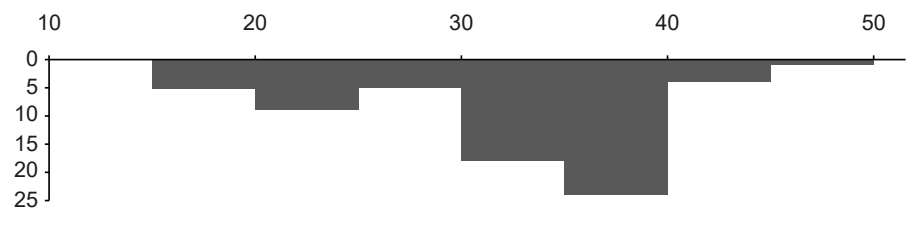


Fig. 5
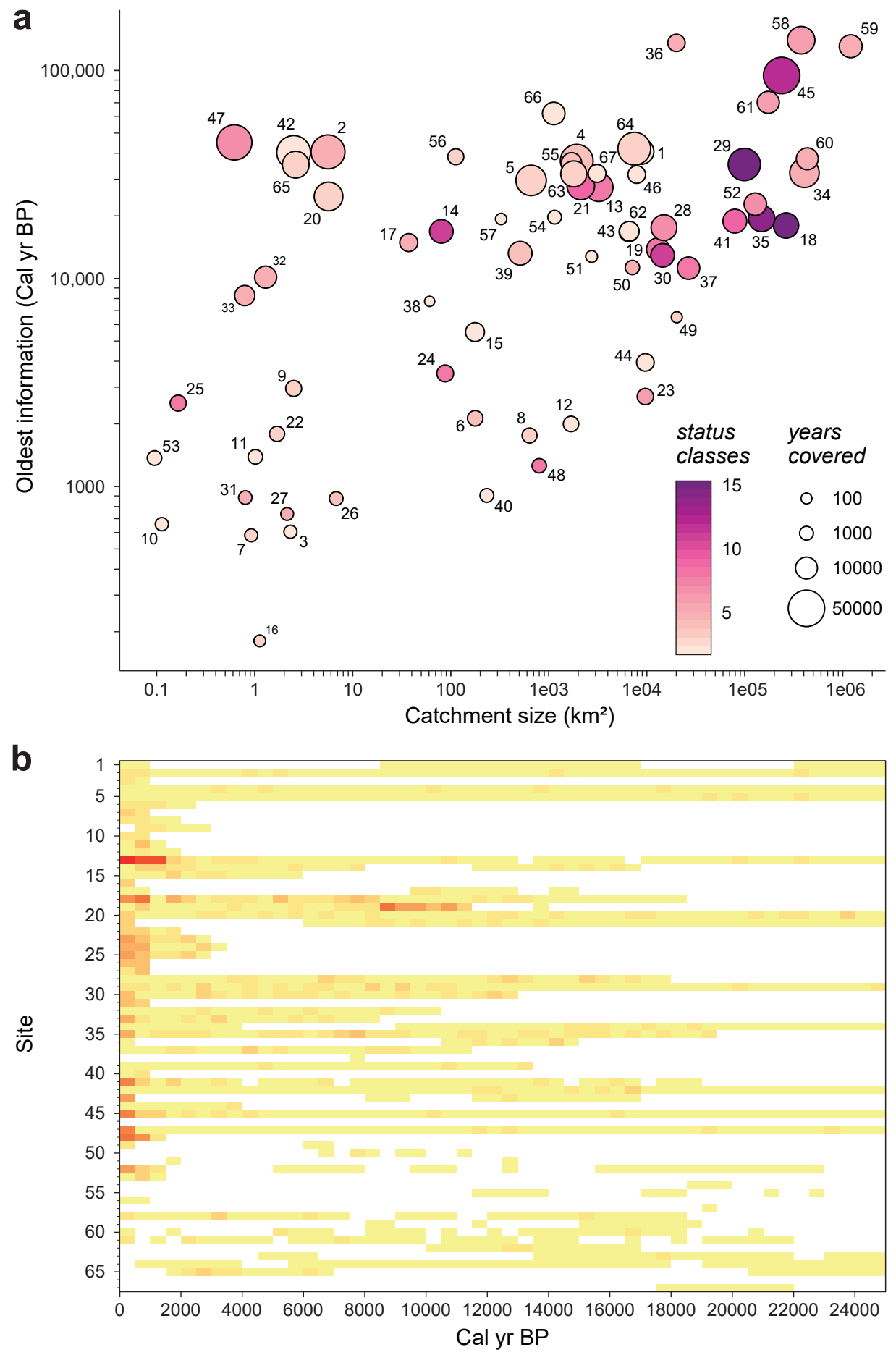

Number of lake-status episodes

$\begin{array}{llllllllllll}1 & 2 & 3 & 4 & 5 & 6 & 7 & 8 & 9 & 10 & 11 & 12\end{array}$ 
a

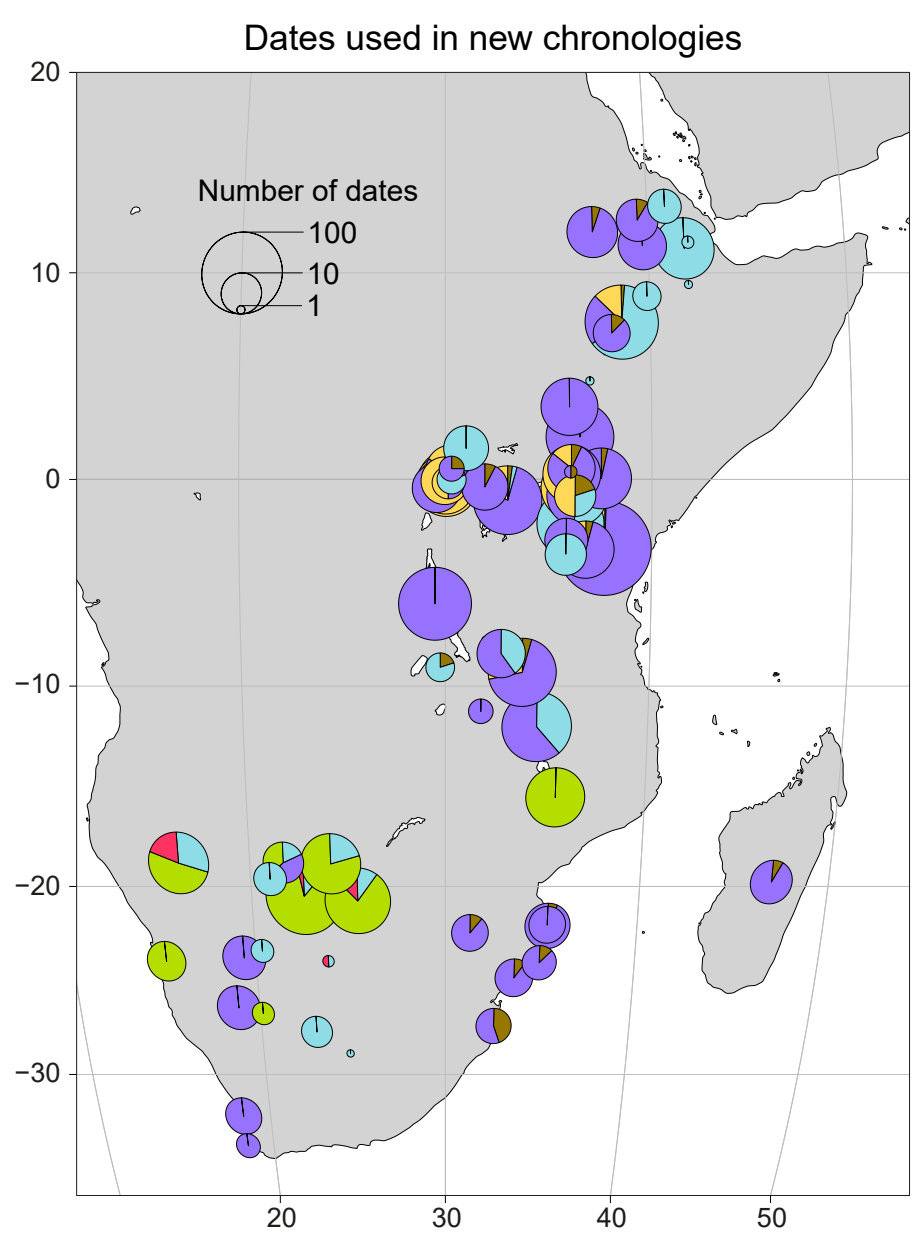

Date type

event

OSL b
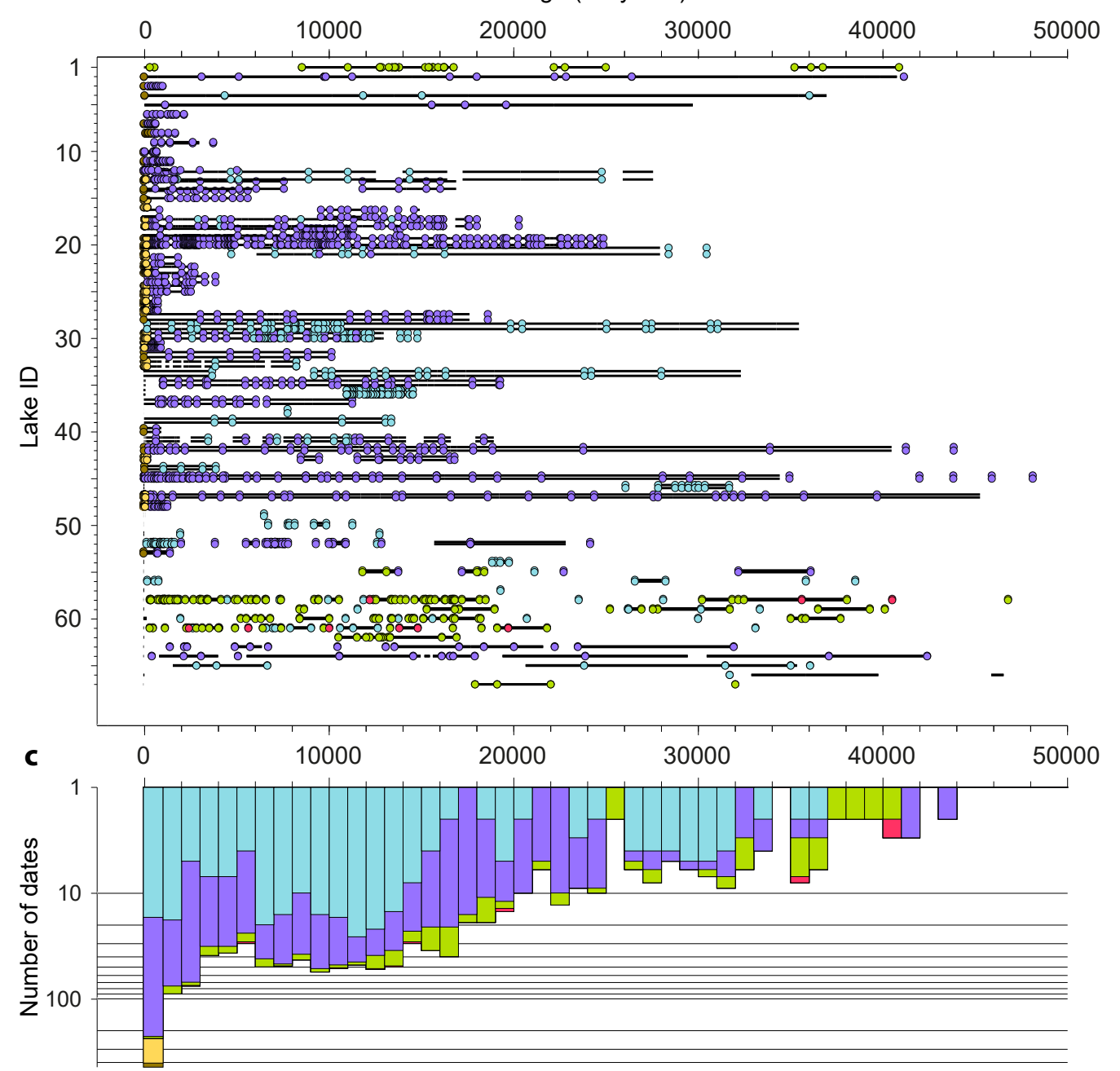

U-Th

radiocarbon

(originally calibrated)

radiocarbon
(originally uncalibrated) $\square$ thermoluminescence 
Fig. 7

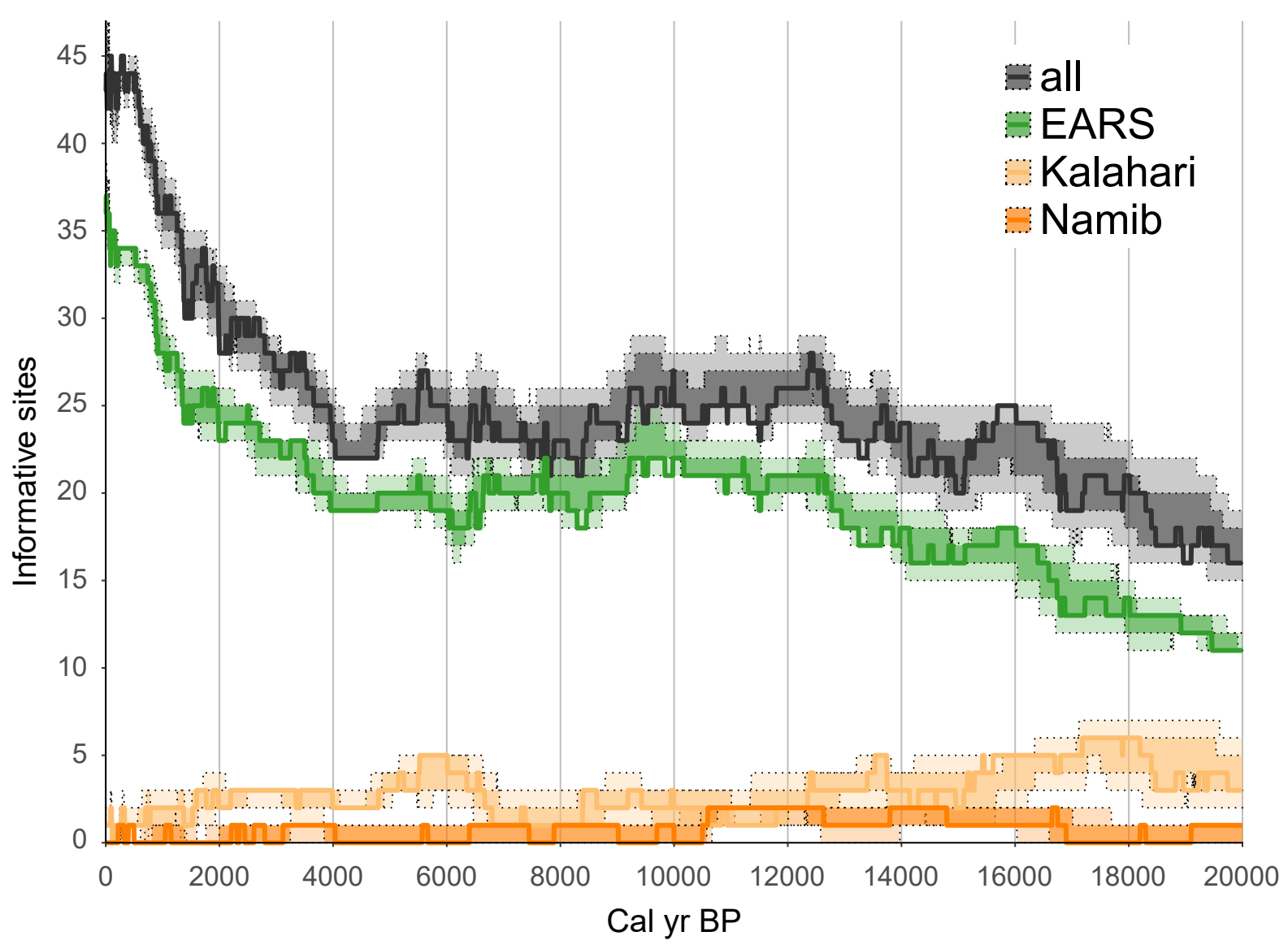





$\% 100 \% \% 100 \% \% 100 \% \% 100 \% \% 100 \% \% 100$

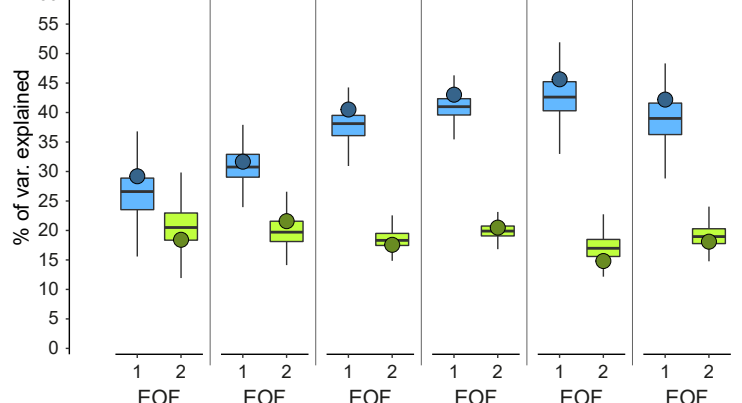

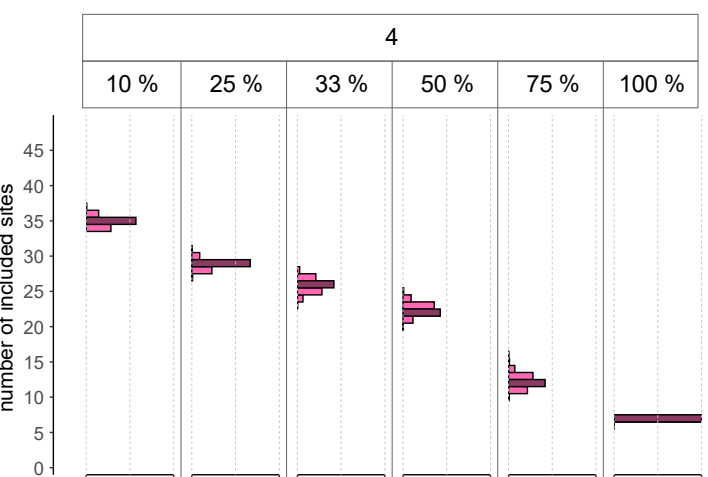
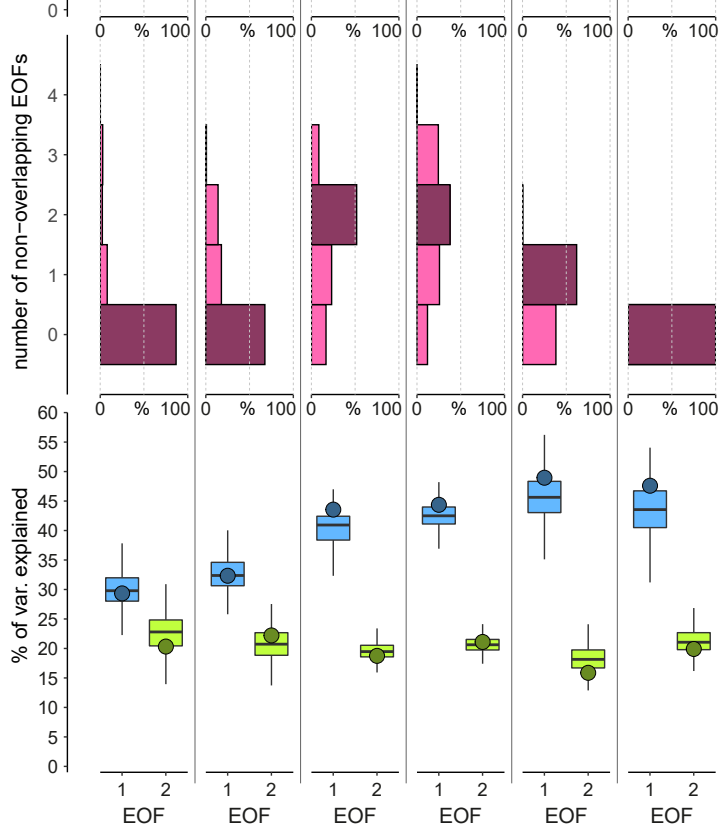

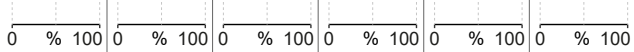

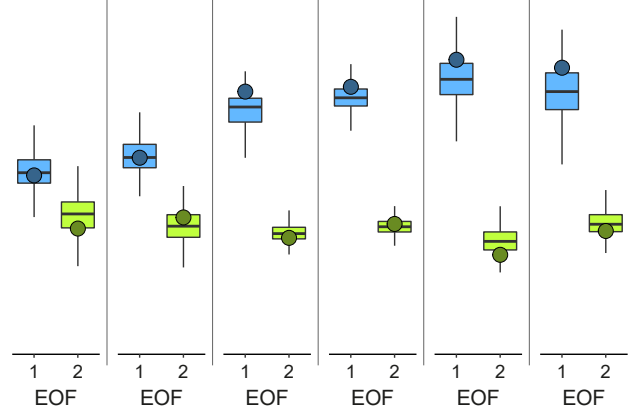

b $\underset{\text { episodes }}{\min }$

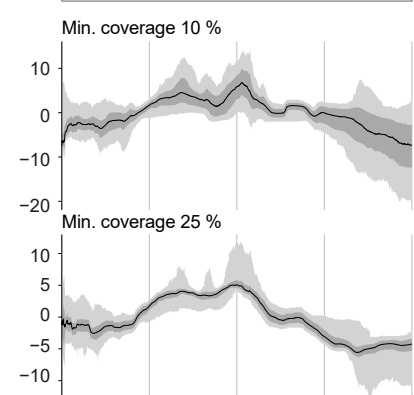

4
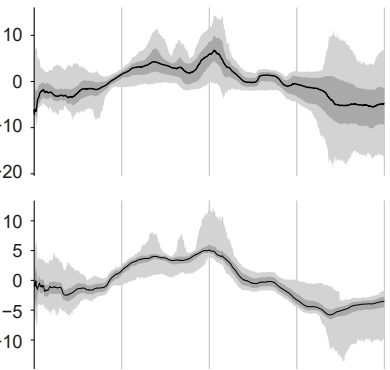

Min. coverage $33 \%$
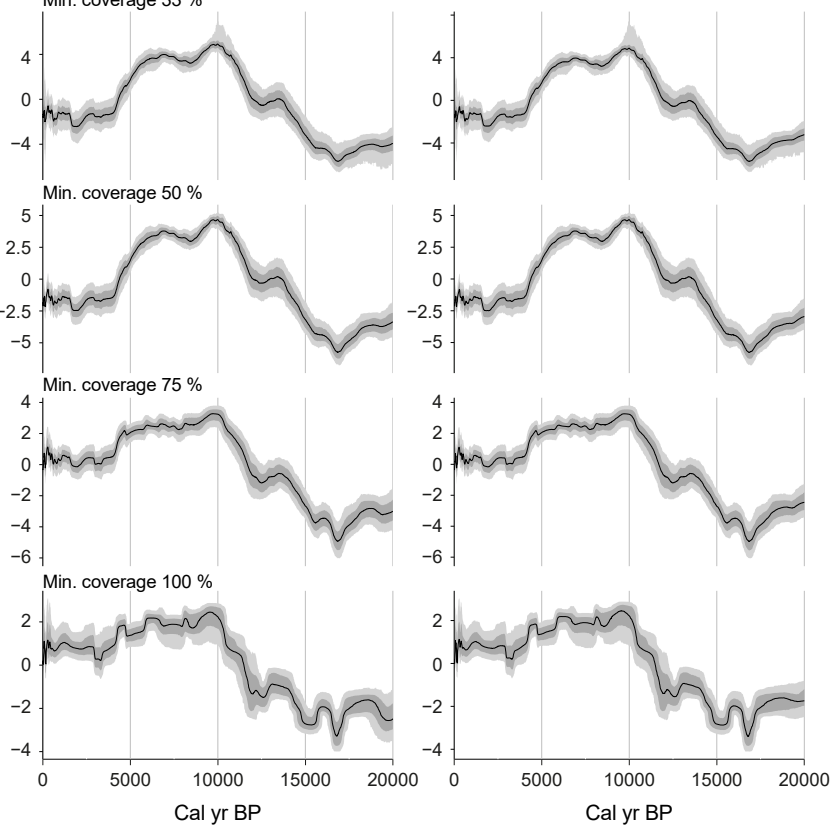
Fig. 9
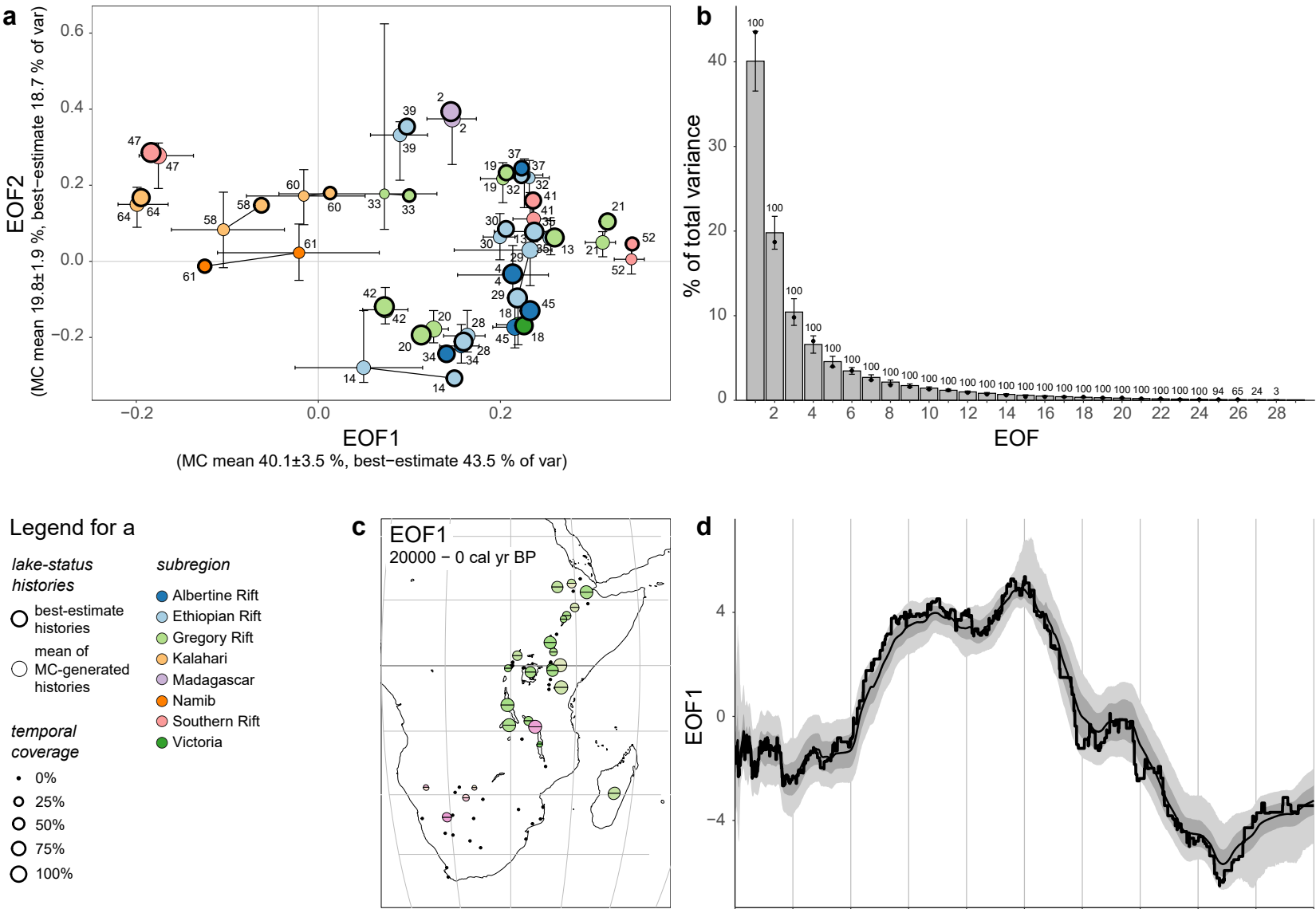

Legend for $\mathrm{c}$ and $\mathrm{e}$

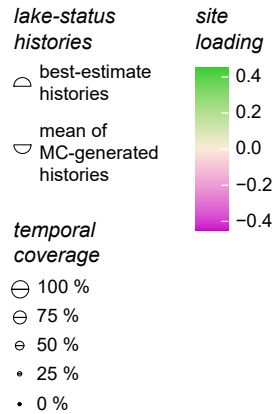

e EOF2

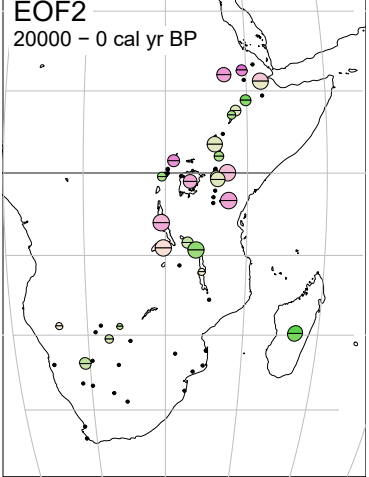

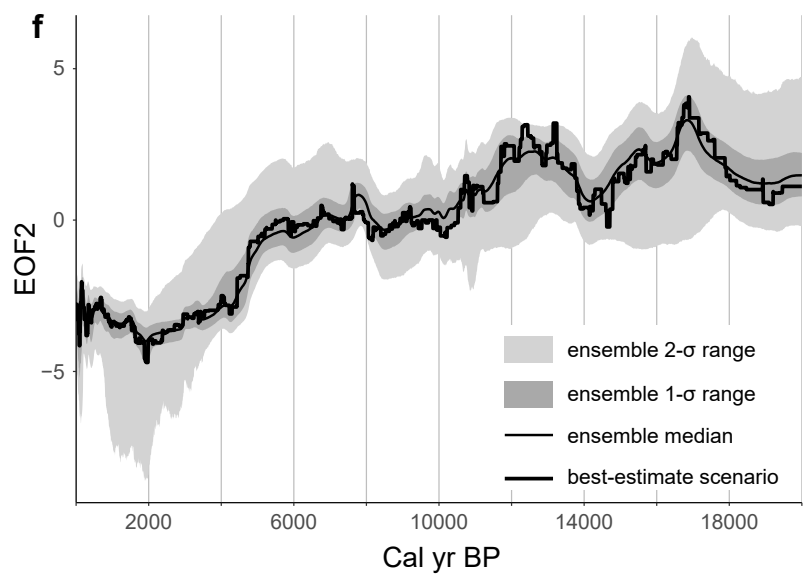

